FEDERAL RESERVE BANK OF SAN FRANCISCO

WORKING PAPER SERIES

\title{
Market-Based Monetary Policy Uncertainty
}

\author{
Michael Bauer \\ Federal Reserve Bank of San Francisco \\ Universität Hamburg and CESifo \\ Aeimit Lakdawala \\ Wake Forest University \\ Philippe Mueller \\ Warwick Business School
}

February 2021

Working Paper 2019-12

https://www.frbsf.org/economic-research/publications/working-papers/2019/12/

\section{Suggested citation:}

Bauer, Michael, Aeimit Lakdawala, Philippe Mueller. 2021. "Market-Based Monetary Policy Uncertainty," Federal Reserve Bank of San Francisco Working Paper 2019-12. https://doi.org/10.24148/wp2019-12

The views in this paper are solely the responsibility of the authors and should not be interpreted as reflecting the views of the Federal Reserve Bank of San Francisco or the Board of Governors of the Federal Reserve System. 


\title{
Market-Based Monetary Policy Uncertainty*
}

\author{
Michael D. Bauer \\ Universität Hamburg and CESifo
}

\author{
Aeimit K. Lakdawala \\ Wake Forest University
}

\author{
Philippe Mueller \\ Warwick Business School \\ First version: August 15, 2018 \\ This version: February 20, 2021
}

\begin{abstract}
Uncertainty about future policy rates plays a crucial role for the transmission of monetary policy to financial markets. We demonstrate this using event studies of FOMC announcements and a new model-free uncertainty measure based on derivatives. Over the "FOMC uncertainty cycle" announcements systematically resolve uncertainty, which then gradually ramps up again over the subsequent two weeks. Changes in monetary policy uncertainty around FOMC announcements - often due to new forward guidancehave pronounced effects on asset prices that are distinct from the effects of conventional policy surprises. Furthermore, the level of uncertainty determines the magnitude of the financial market reaction to surprises about the path of policy rates.
\end{abstract}

Keywords: monetary policy uncertainty, Federal Reserve, event study, monetary transmission, jumps, implied volatility, asset prices

JEL Classifications: E44, E52, E58, G10

${ }^{*}$ We thank Ruslan Bikbov, Mike Chernov, Rodrigo Sekkel (discussant), and seminar participants at various seminars and conferences for their helpful comments; Brent Bundick and Eric Swanson for sharing their interest-rate uncertainty measures; and Shannon Sledz, Patrick Shultz, and Simon Zhu for excellent research assistance. Bauer: michael.d.bauer@gmail.com, Lakdawala: lakdawa@wfu.edu, Mueller: philippe.mueller@wbs.ac.uk. 


\section{Introduction}

In order to better understand the transmission of monetary policy to financial markets, a large literature has studied the effects of changes in expected policy rates in event studies of FOMC announcements with high-frequency data. ${ }^{1}$ However, the role of second moments and uncertainty has received much less attention in this context. In this paper, we use a market-based measure of uncertainty about future short-term interest rates to document new findings about the drivers of policy uncertainty and the effects of uncertainty on asset prices.

The paper makes three main contributions. First, we introduce a new uncertainty measure based on prices of Eurodollar futures and options, the market-based conditional volatility of the future short-term interest rate. The measure is model-free, derived from prices of highly liquid interest rate derivatives, and available at a daily frequency for a long sample period. This allows us to use event studies to investigate changes in short-rate uncertainty around FOMC announcements, when changes in this uncertainty are primarily driven by changes in monetary policy uncertainty.

Second, we document the underlying drivers of changes in monetary policy uncertainty, including an "FOMC uncertainty cycle." On average, FOMC announcements cause uncertainty to fall, in line with a systematic resolution of uncertainty. Over the first two weeks after the announcement, uncertainty then gradually ramps up again. We investigate other events as potential drivers of uncertainty, such as macroeconomic news releases and speeches by FOMC participants, and none can match the impact of FOMC announcements on short-rate uncertainty.

Beyond this pattern over the FOMC cycle, monetary policy uncertainty exhibits substantial variation across FOMC announcements and systematically responds to specific Fed policy actions. In particular, forward guidance announcements typically lower uncertainty: FOMC meetings that are followed by the release of a Summary of Economic Projections (SEP) and

\footnotetext{
${ }^{1}$ See, e.g., Cook and Hahn (1989), Kuttner (2001), Bernanke and Kuttner (2005), Gürkaynak et al. (2005a), Hanson and Stein (2015), or Nakamura and Steinsson (2018).
} 
a press conference lead to larger declines in uncertainty than other FOMC meetings over the same period (since 2012). A narrative analysis reveals that the most pronounced changes in policy uncertainty result from changes in the forward guidance language in the FOMC statement. While policy actions often move expectations and uncertainty about future policy rates in the same direction, the effects on uncertainty are a separate dimension of FOMC announcements. For example, some forward guidance announcements, such as the introduction of calendar-based guidance in August 2011, only caused a modestly dovish policy surprise as conventionally measured, but substantially lowered uncertainty. While Gürkaynak et al. (2005a) emphasize the need to distinguish between surprises in current and expected future policy rates, our results imply that another relevant distinction is between changes in the level of the expected policy path and in the uncertainty around this future path.

Our findings - which are robust to the choice of sample period, the exclusion of influential observations, and different horizons for uncertainty - can be interpreted through the lens of a simple short-rate model with deterministic jumps at FOMC announcement dates. Uncertainty tends to sharply decline around announcements and then gradually increase due to the changing number of FOMC jumps contributing to conditional volatility. Further variation in policy uncertainty is due to changes in beliefs about the volatility of future jumps, likely due to forward guidance by the Fed. ${ }^{2}$

The third contribution of the paper is to document an uncertainty channel for the transmission of FOMC actions to financial markets: Changes in policy uncertainty have significant effects on asset prices that are distinct from the effects of shifts in expectations, i.e., from the effects of conventional measures of the policy surprise. ${ }^{3}$ An increase in uncertainty around FOMC announcements raises nominal and real long-term interest rates, has a negative effect on the stock market - lowering S\&P 500 returns and increasing the VIX - and causes the dollar

\footnotetext{
${ }^{2}$ Additional evidence indicates the presence of substantial FOMC jump risk premia.

${ }^{3}$ While we focus on transmission to U.S. financial markets in this paper, in follow-up work Lakdawala et al. (2020) show that this effect spills over to international bond and equity markets in both advanced and emerging economies.
} 
to appreciate. An event study of unconventional monetary policy announcements shows that balance sheet policies and forward guidance substantially lower perceived monetary policy uncertainty, contributing to their effectiveness in easing financial conditions. The uncertainty channel appears to be particularly powerful when the zero lower bound constrains the policy rate and the main lever for forward guidance announcements is to affect second moments. The direction of the estimated effects on asset prices is consistent with a risk-based explanation: In standard asset-pricing models, higher uncertainty raises risk premia, leading to higher real and nominal yields and lower stock prices. ${ }^{4}$

Our evidence on the uncertainty channel may help explain the puzzling large responses of long-term interest rates and other asset prices to Fed policy surprises that previous studies have documented; see, for example, Hanson and Stein (2015). Changes in the expected policy path are positively related to uncertainty: hawkish policy surprises are associated with smaller-thanaverage declines in uncertainty (or even increases) while dovish surprises are associated with larger declines. Since first-moment surprises are positively correlated with second-moment changes, and uncertainty has pronounced effects on asset prices, leaving out uncertainty in the common event-study regressions may cause an upward bias in the estimated effects of monetary policy surprises. We avoid this problem by accounting for the effects of monetary policy uncertainty on asset prices.

Finally, the level of short-rate uncertainty also matters for the transmission of policy actions to financial markets: At high levels of uncertainty, monetary policy surprises have much more muted effects on asset prices than when uncertainty is low. This empirical pattern is consistent with a signal-extraction logic that investors put higher weight on signals from the Fed when they are more confident about the expected policy path. ${ }^{5}$

The paper is most closely related to the literature that uses market-based measures of second moments to study the role of risk and uncertainty in the transmission of monetary

\footnotetext{
${ }^{4}$ Additional evidence about the response of term premia to changes in uncertainty supports this explanation.

${ }^{5}$ This finding dovetails existing evidence that during periods of high uncertainty, monetary policy shocks have more muted effects on the macroeconomy (Aastveit et al., 2017; Tillmann, 2020).
} 
policy to financial markets. In an early contribution, Swanson (2006) documents that optionbased short-rate uncertainty declines between 1989 and 2003, and that starting in 1994 it tends to fall around FOMC announcements, a fact he attributes to increased Fed transparency. We extend the evidence on the resolution of uncertainty and explain this pattern with FOMC jumps. Bundick et al. (2017) estimate positive effects of changes in short-rate uncertainty on term premia around FOMC announcements. We establish that changes in policy uncertainty affect a broad range of asset prices, including real and nominal bonds, stocks, and exchange rates and provide a risk-based explanation that is consistent with such term premium effects. ${ }^{6}$ De Pooter et al. (2021) also find that the response of long-term yields to monetary policy surprises depends on the level of short-rate uncertainty, and propose an explanation based on the bond inventory management of Primary Dealers. Our results show that this level effect is present in all asset price responses, and we propose a more general explanation based on signalextraction logic and investors' confidence about the future policy rate path. Finally, Kroencke et al. (2019) document an "FOMC risk shift" as a separate dimension of FOMC announcement effects. They identify this risk-shift by changes in risk spreads and the VIX that are orthogonal to the conventional (first-moment) policy surprise, and show that this measure is correlated with stock returns. They hypothesize an "uncertainty channel" of policy announcements for which we provide direct evidence. ${ }^{7}$

A quickly growing literature measures policy uncertainty using different text-based or

\footnotetext{
${ }^{6}$ In contrast to Bundick et al. (2017), our event-study regressions control for conventional policy surprises, which is important due to their correlation with changes in uncertainty.

${ }^{7}$ In older work, Ederington and Lee (1996) and Beber and Brandt (2006) document declines in optionimplied interest rate volatility around macroeconomic announcements. We show that the resolution of uncertainty on FOMC days is much more pronounced than on macro announcement days. Other papers that also use market-based measures of short-rate uncertainty and investigate the effects of monetary policy include Neely (2005), Emmons et al. (2006), and Chang and Feunou (2013). Bundick and Herriford (2017) show that short-rate uncertainty has declined since the FOMC started releasing its Survey of Economic Projections. In subsequent work, Chatterjee et al. (2020) find a reduction of swaption implied volatility around FOMC announcements. Lucca and Moench (2015) and Mueller et al. (2017) document profitable trading strategies around FOMC meetings, related to our results on an option-based strategy that benefits from declining uncertainty around FOMC announcements. In addition, several papers have shown that the VIX tends to fall around FOMC announcements (Fernandez-Perez et al., 2017; Amengual and Xiu, 2018; Gu et al., 2018). Finally, Benamar et al. (2020) investigate the role of uncertainty for the response of yields to macroeconomic news.
} 
model-based approaches. In a landmark contribution, Baker et al. (2016) propose a methodology to measure policy uncertainty based on newspaper coverage. Husted et al. (2020) leverage this methodology to create an index of monetary policy uncertainty. Using state-of-the-art time series methods, Fernández-Villaverde et al. (2015) and Creal and Wu (2017) estimate fiscal and monetary policy rules, respectively, and measure policy uncertainty as the stochastic volatility of the rules' innovations. Each of these methods has its own unique advantages. What distinguishes our market-based measure is that it has a very clear economic interpretation as the conditional volatility of the future short rate, and that it is available at a daily frequency, which is crucial when using event studies to investigate the role of uncertainty in financial markets.

\section{Measuring short-rate uncertainty with option prices}

While long-term interest rates are driven by expectations of future short rates, market-based estimation of the uncertainty around these expectations requires option prices, which reflect information about the entire distribution of future short rates. We use daily prices of Eurodollar futures and options from CME Group for the period from January 1994 to September 2020. The advantages of these exchange-traded interest rate derivatives include their high liquidity, long maturity horizons, and extensive historical data availability. Their underlying rate is the three-month U.S. dollar London Interbank Offered Rate, or LIBOR, a benchmark short-term interest rate. For any trading day $t$ and option expiration date $T$, we use the prices of out-ofthe-money options to calculate the implied conditional variance of future LIBOR, $L_{T}$, that is, a market-based estimate of $\operatorname{Var}_{t}\left(L_{T}\right)$. The methodology is based on modern variance swap theory (like the VIX), and Appendix A.1 contains the details. Our market-based short-rate uncertainty is the conditional standard deviation, $S R U_{t, T}=\left[\operatorname{Var}_{t}\left(L_{T}\right)\right]^{1 / 2}$, measured in percentage points. For most of what follows we use a constant-maturity measure that is linearly interpolated to a one-year horizon. 
Figure 1: Option-based estimate of short-rate uncertainty

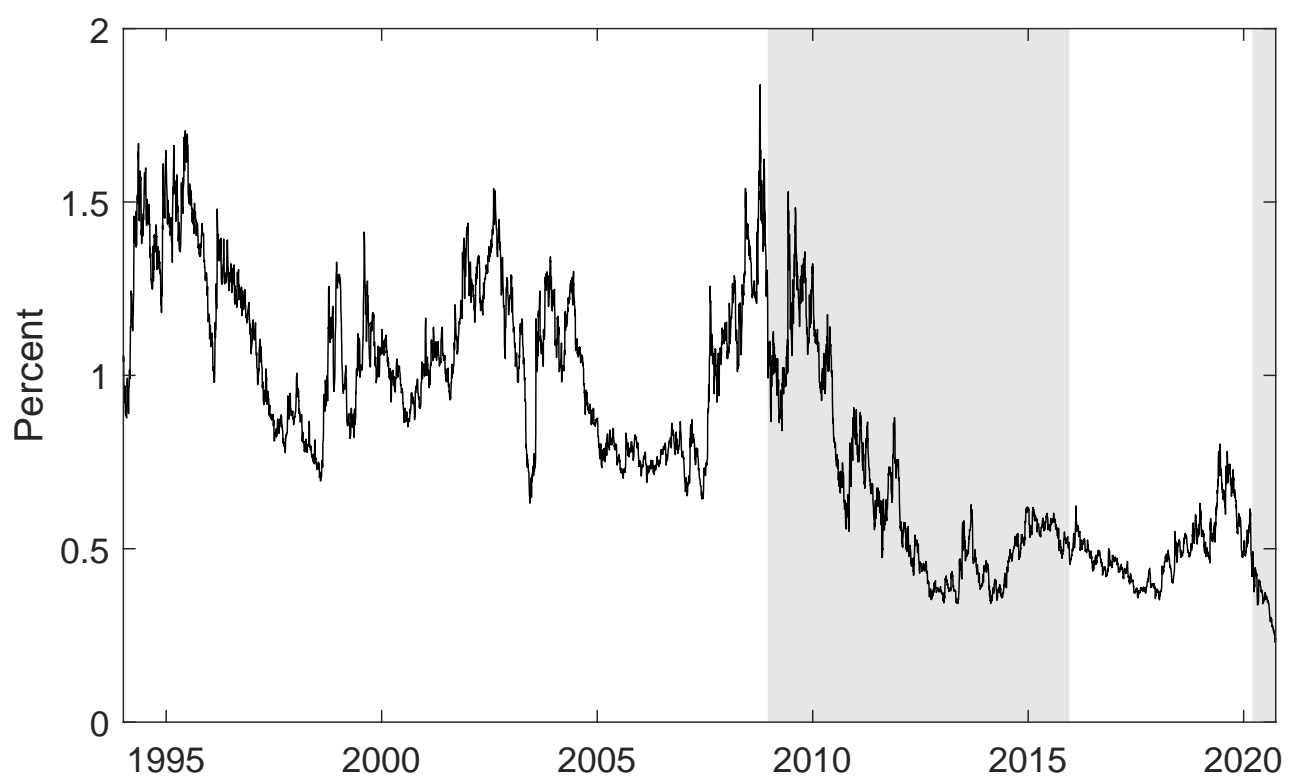

Risk-neutral standard deviation of three-month LIBOR rate at a one-year horizon, estimated from Eurodollar futures and options. Gray-shaded areas show ZLB periods. Sample period: $1 / 3 / 1994$ to $09 / 30 / 2020$.

Figure 1 plots the time series of $S R U$ from 1994 to 2020. Uncertainty exhibits considerable variation, ranging from about 0.2 to two percent, and a pronounced downward trend that is only briefly interrupted by a period of elevated uncertainty during the financial crisis in $2008 .{ }^{8}$ One possible explanation for the secular decline in uncertainty is the increasing transparency of the Fed about its monetary policy decisions, including ever more extensive use of forward guidance (Swanson, 2006). During the two zero-lower-bound (ZLB) periods the Fed's forward guidance appears to play an important role in lowering uncertainty. In the first ZLB episode $S R U$ at first remained elevated due to uncertainty about possible liftoff but then dropped to very low levels with the introduction of extensive forward guidance in 2011. During the second ZLB episode during the COVID pandemic $S R U$ reaches an all-time low, potentially

\footnotetext{
${ }^{8}$ There is a moderate positive correlation between the level of interest rates and uncertainty, consistent with existing findings of a positive relationship between the level and volatility of short rates (Chan et al., 1992): Comparing the one-year interpolated Eurodollar futures rate (not shown) to one-year $S R U$, the correlation is 0.6 in levels and 0.4 in daily changes.
} 
again driven by extensive forward guidance from the Fed.

But interpreting the changes in $S R U$ shown in Figure 1 is difficult. Uncertainty about future short rates can arise both from uncertainty about monetary policy, i.e., about the Fed's policy actions, as well as from uncertainty about the economic outlook. Given the two-way endogenous feedback between economic conditions and monetary policy, a structural dynamic model would be required for a meaningful decomposition into pure monetary policy uncertainty on the one hand and macro uncertainty on the other hand. ${ }^{9}$ We take a different route to overcome this identification challenge by instead focusing on daily changes in $S R U$ around the Fed's monetary policy announcements. In doing so, we follow a large existing event-study literature that takes advantage of the fact that over short event windows, these announcements are the key drivers of asset prices. Since these changes in $S R U$ are caused by the FOMC announcements, we refer to them as monetary policy uncertainty $(M P U)$. The traditional view of central bank communication is that monetary policy announcements contain new information about the conduct of monetary policy (i.e., the Fed's reaction function or policy shocks). In addition, as emphasized by a more recent literature on central bank "information effects," such announcements may also directly affect beliefs and uncertainty about the economic outlook, although recent work by Bauer and Swanson (2020) suggests that there is little evidence for such information effects. Here, however, we do not need to take a stand on this issue: Our goal is simply to capture all effects due to changes in uncertainty around FOMC announcements, and to investigate their role in the transmission of the Fed's policy actions to financial markets.

Before turning to the event-study analysis, we discuss a few issues related to the measurement of uncertainty. Given our focus on monetary policy, a disadvantage of Eurodollar derivatives is that their underlying rate is LIBOR. Because the spread between LIBOR and

\footnotetext{
${ }^{9}$ Appendix B shows that several commonly used macro uncertainty measures have only a very modest correlation with $S R U$. There, we also discuss the issues and different possible approaches for decomposing short-rate uncertainty into macro and policy uncertainty in the context of a structural model, the canonical three-equation New Keynesian model.
} 
the Fed's policy rate varies over time, $S R U$ also captures uncertainty about changes in this spread. Appendix A.2 shows that the spread exhibits pronounced variation and sudden spikes during the financial crisis from July 2007 to June 2009. Outside of this period, however, the spread is remarkably stable. Therefore, our pragmatic solution is to exclude this period from our sample, and to rely on the assumption that over our sample period $S R U$ mainly reflects uncertainty about the future value of the policy rate.

Our $S R U$ series, which could be called "model-free basis point volatility" for LIBOR, has several advantages over other commonly used market-based measures of interest-rate uncertainty: It is model-free (instead of relying on distributional assumptions or even just the absence of jumps), it incorporates information from a range of strike prices (instead of only at-the-money $[$ ATM] contracts), it uses prices of exchange-traded option contracts (instead of potentially stale quotes or over-the-counter prices), and it provides a market-based measure of the conditional volatility of the future short-term interest rate (instead of uncertainty about medium- or long-term rates or about returns). Table 1 compares $S R U$ to other interest-rate uncertainty measures that do not have all of these advantages. ${ }^{10}$ Basis point volatility is the product of Black implied volatility (IV) with the futures price, and we interpolate to a constant one-year horizon as well. This measure has a mean modestly below that of $S R U$, because it uses only ATM options and misses some additional uncertainty that is present in the tails of the distribution and reflected in out-of-the-money options. The volatility is similar to that of $S R U$, both for levels and changes, and the levels of the two series are very highly correlated. However, for daily changes, which are the main focus of our subsequent analysis, the correlation is only 0.86 , which raises a warning flag against exclusively relying on ATM options and the Black model for investigating changes in short-rate uncertainty. Two other model-free volatility measures using Eurodollar options have been proposed in other work. Bundick et al. (2017) use the well-known VIX formula, resulting in an approximate IV for changes in LIBOR. Table 1 reports results for IV at the four-quarter horizon, which

\footnotetext{
${ }^{10}$ Appendix A.3 provides more details and a visual comparison.
} 
Table 1: Comparison of market-based measures of interest-rate uncertainty

\begin{tabular}{lccccccc}
\hline Measure & $E\left(U_{t}\right)$ & $\sigma\left(U_{t}\right)$ & $\sigma\left(\Delta U_{t}\right)$ & $\rho\left(U_{t}, S R U_{t}\right)$ & $\rho\left(\Delta U_{t}, \Delta S R U_{t}\right)$ & Period & Obs. \\
\hline SRU & 0.902 & 0.341 & 0.023 & 1.000 & 1.000 & $01 / 1990-09 / 2020$ & 7756 \\
BP vol & 0.858 & 0.352 & 0.027 & 0.995 & 0.861 & $01 / 1990-09 / 2020$ & 7756 \\
Bundick & 1.167 & 0.259 & 0.036 & 0.969 & 0.688 & $01 / 1994-12 / 2008$ & 3782 \\
Swanson & 1.420 & 0.520 & 0.139 & 0.908 & 0.339 & $10 / 1995-12 / 2012$ & 4337 \\
Swaption IV & 0.706 & 0.308 & 0.023 & 0.964 & 0.688 & $05 / 2005-09 / 2020$ & 3764 \\
SRVIX & 0.803 & 0.102 & 0.008 & 0.045 & 0.395 & $06 / 2012-09 / 2020$ & 2068 \\
MOVE & 0.921 & 0.275 & 0.040 & 0.766 & 0.438 & $01 / 1990-09 / 2020$ & 7751 \\
TIV/TYVIX & 6.715 & 1.883 & 0.519 & 0.669 & 0.211 & $01 / 1990-05 / 2020$ & 7598 \\
\hline
\end{tabular}

Summary statistics for daily market-based measures of interest-rate uncertainty. $B P$ vol: basis point volatility (Black IV multiplied by futures price) for ATM Eurodollar options, interpolated (as $S R U$ ) to the one-year horizon. Bundick: model-free IV measure for Eurodollar options from Bundick et al. (2017) at a four-quarter horizon. Swanson: short-rate uncertainty measure of Swanson and Williams (2014). Swaption IV: normal vol for 1y-1y ATM swaptions. SRVIX: CBOE interest rate volatility index based on 1y-10y swaptions. MOVE: weighted average of $\mathrm{BP}$ vol for $1 \mathrm{~m}$ Treasury options. TIV/TYVIX: model-free IV for $1 \mathrm{y}$ options on $10 \mathrm{y}$ T-Note futures from Choi et al. (2017). For each series $U_{t}$ the table reports the mean, volatility of levels and daily changes, correlation with $S R U$ in levels and changes, available sample period, and number of daily observatiosn.

has similar properties to $S R U$ but with a correlation of daily changes of below 0.7. Swanson (2006) calculates an uncertainty measure, later used in Swanson and Williams (2014), as the interquintile range of an option-based probability distribution. This series is a fair amount more volatile than ours, and changes in the two are not very highly correlated.

Financial professionals typically measure interest-rate uncertainty using swaptions or Treasury derivatives, and we consider four popular measures in Table 1. Among them, Swaption IV, which is the normal vol (i.e., IV assuming a normal distribution) of ATM 1y-1y swaptions, is the most closely related to our measure, though the correlation of daily changes is still below 0.7. The SRVIX, a relatively new model-free interest rate volatility index from CBOE that is based on 1y-10y swaptions, has a correlation with our measure (and with other measures) that is surprisingly low. ${ }^{11}$ The long-standing MOVE index, a weighted average of basis point vol for one-month Treasury options across bond maturities, as well as the "Treasury Implied Volatility" (TIV) index of Choi et al. (2017) that is essentially identical to the TYVIX from

\footnotetext{
${ }^{11}$ Swaption IVs and the SRVIX are based on over-the-counter prices.
} 
Bloomberg, both have only moderate correlation with our preferred measure. ${ }^{12}$ All of these series measure uncertainty about medium- or long-term interest rates, which reflect not only expected future short rates but also a time-varying term premium. Therefore, these alternative measures are not suitable for analyzing uncertainty about short-term interest rates and monetary policy, which is the purpose of our study.

Market-based uncertainty measures reflect not only the true uncertainty but also a potentially time-varying variance risk premium (Choi et al., 2017). Analogously, market interest rates reflect not only expected future overnight rates but also a term premium. In this paper, we follow the tradition in the macro-finance literature of using market-based measures in monetary policy event studies. Our model-free approach ensures that we accurately capture, on a day-to-day basis, how investors perceive and value the uncertainty about future short rates. $^{13}$

\section{Changes in uncertainty around FOMC announcements}

The first step of our event-study analysis is to characterize and understand changes in $S R U$ around FOMC announcements. As discussed above, these daily changes are mainly driven by the monetary policy announcements, so we refer to "monetary policy uncertainty" and denote these changes by $M P U$.

FOMC announcements and policy actions typically lead to a substantial resolution of uncertainty about the future path of interest rates. Figure 2 plots $M P U$ for all 229 FOMC announcements between January 1994 and September 2020, and shows that uncertainty declines around most of them (188 or $82 \%$ ). Table 2 shows summary statistics for the 197 announcements that followed regularly scheduled FOMC meetings and occurred outside the

\footnotetext{
${ }^{12}$ We splice together the historical data for the TIV index with the more recent data for TYVIX (which was discontinued in May 2020), using the average of the two series from 2002 to 2015 when both are available.

${ }^{13}$ Further separating statistical variance from variance risk premia requires a dynamic model for volatility (as in Bekaert et al., 2013) which entails substantial estimation and specification uncertainty.
} 
Figure 2: Changes in monetary policy uncertainty around FOMC announcements

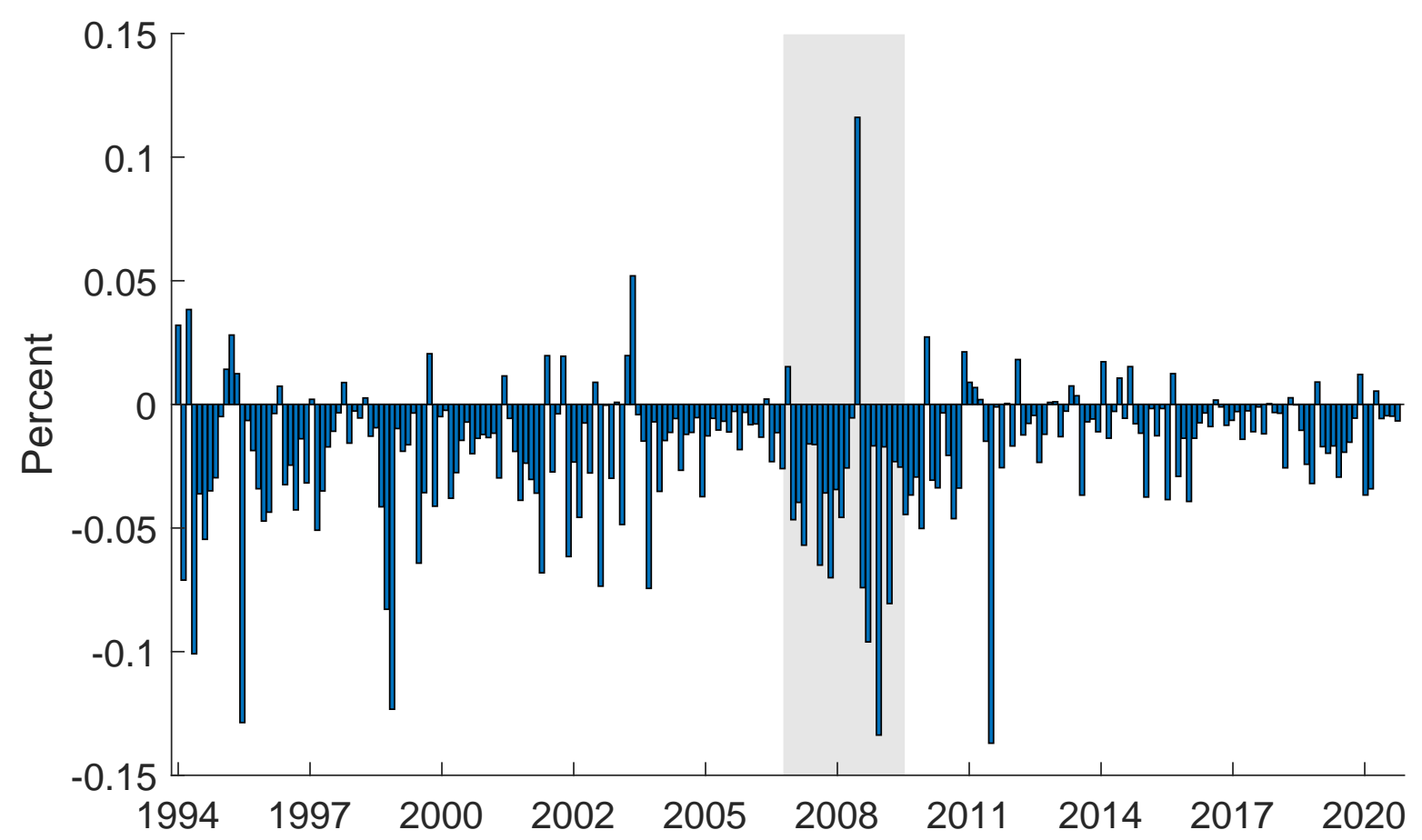

Changes in monetary policy uncertainty on days with FOMC announcements, or MPU. Sample includes all 229 FOMC announcements from January 1994 to September 2020. Shaded region shows the period from July 2007 to June 2009 containing the Global Financial Crisis.

period from July 2007 to June 2009 containing the Global Financial Crisis. ${ }^{14}$ The first column reports an average decline on FOMC days of 1.6 basis points (bps), which is both highly statistically significant and large in magnitude, compared to the standard deviation of $2.5 \mathrm{bps}$ on FOMC days and 1.9 bps on other days. Negative skewness arises from the frequent large declines in uncertainty evident in Figure 2. The resolution of uncertainty around FOMC meetings contrasts with the average change on non-FOMC days, reported in the second column, which is essentially zero. ${ }^{15}$

The Federal Reserve has made substantial changes to the way the outlook for the economy

\footnotetext{
${ }^{14}$ All our results remain essentially unchanged when we include the unscheduled FOMC announcements.

${ }^{15}$ Our results are based on daily uncertainty estimates and leave open the question of when exactly uncertainty gets resolved around the release of an FOMC announcement. Pre-announcement effects in stock prices (Lucca and Moench, 2015) and the VIX (Hu et al., 2019) suggest that some uncertainty might decline before the actual FOMC announcement. While we cannot conclusively answer this question with daily data, our evidence below that link $M P U$ to changes in the FOMC statement language, as well as further evidence in Appendix D.1 on pre-announcement effects, on the whole is most consistent with the view that changes in uncertainty occur in response to the actual announcement.
} 
Table 2: Summary statistics for changes in uncertainty

\begin{tabular}{lccccccc}
\hline & \multicolumn{2}{c}{ Jan. 1994 to Sep. 2020 } & & \multicolumn{3}{c}{ Jan. 2012 to Dec. 2018 } \\
\cline { 2 - 3 } \cline { 6 - 7 } & FOMC & Non-FOMC & & All FOMC & With SEP & W/o SEP \\
\hline Observations & 197 & 6032 & & 56 & 29 & 27 \\
Mean & -0.016 & 0.000 & & -0.008 & -0.013 & -0.002 \\
$t$-statistic & -8.94 & 1.37 & & -4.60 & -5.12 & -1.35 \\
Standard deviation & 0.025 & 0.019 & & 0.013 & 0.014 & 0.009 \\
Skewness & -1.64 & 1.31 & & -0.56 & -0.33 & 0.68 \\
Cumulative change & -3.16 & 2.08 & & -0.44 & -0.38 & -0.06 \\
\hline
\end{tabular}

Summary statistics for changes in $S R U$, the market-based standard deviation for the short-term interest rate one year into the future, measured in percentage points. $t$-statistics are based on White heteroscedasticityrobust standard errors. The first two columns report results for our baseline sample period from January 1994 to September 2020, excluding the period from July 2007 to June 2009 containing the Global Financial Crisis. The last three columns focus on the period from January 2012 to December 2018, when every alternate FOMC meeting was followed by a press conference and release of the Summary of Economic Projections (SEP).

and interest rates is communicated to the public. Most significant are the press conferences held by the Chair and the release of the economic forecasts of the FOMC participants, the "Summary of Economic Projections" (SEP). ${ }^{16}$ Through these communication channels the Committee provides more information about economic fundamentals and the rationale underlying the policy actions. From January 2012 to December 2018, the FOMC released the SEP and held a press conference after every other FOMC meeting. The last three columns of Table 2 show summary statistics for this period, comparing those meetings with and without an SEP release. Policy uncertainty declined mainly around SEP meetings, while the average change around other meetings is small and not significantly different from zero. Thus, it appears that the release of this extra information about the policy and economic outlook through the SEP and press conference contributes in a meaningful way to the resolution of policy uncertainty. ${ }^{17}$

\footnotetext{
${ }^{16}$ In October 2007, the FOMC began releasing the SEP together with the Minutes three weeks after the FOMC meeting and since April 2011 the SEP is released on the same day as the FOMC statement. In April 2011 Chairman Ben Bernanke also started the tradition of holding regular press conferences at every other FOMC meeting; since January 2019, every meeting is followed by a press conference. From January 2012 onwards the FOMC also started releasing committee members' projections for the appropriate future path of the policy rate as part of the SEP, the so-called "dot plot."

${ }^{17}$ Consistent with this interpretation, Boguth et al. (2019) find that more attention is being paid to these particular FOMC meetings. Bundick and Herriford (2017) also investigate the impact of SEP releases on monetary policy uncertainty, but focusing on the level instead of changes: They show that short-rate uncertainty
} 
A simple model of the short-term interest rate helps with the interpretation of our empirical results. Since FOMC announcements generally follow a known schedule and often lead to substantial changes in asset prices (Gürkaynak et al., 2005a; Bauer, 2015), the model includes jumps in the short rate that occur at deterministic times, as in Piazzesi (2001). The details of the model are in Appendix C, which also reports additional empirical results on the importance of jumps and jump risk premia. The short rate $L_{t}$ follows a jump-diffusion process with diffusion variance $\sigma^{2}$. Jump $j$ occurs at time $t=\tau_{j}$ and has stochastic jump size $Z_{j}$, which is Gaussian with zero mean and jump variance $\sigma_{j}^{2}$. On the day of the FOMC announcement corresponding to this jump, the change in the conditional variance for the future short rate is

$$
\operatorname{Var}_{t}\left(L_{T}\right)-\operatorname{Var}_{t-\delta}\left(L_{T}\right)=-\delta \sigma^{2}-\sigma_{j}^{2}+\sum_{i: t<\tau_{i} \leq T}\left(E_{t}-E_{t-\delta}\right) Z_{i}^{2}
$$

where $\delta$ is the length of a trading day in years. Aside from the passing of time which results in lower diffusion variance for a fixed expiration $\left(-\delta \sigma^{2}\right)$, uncertainty changes for two reasons. First, it systematically declines around FOMC meetings because after the meeting there is one less market-moving event causing uncertainty. This "dropping-out" effect is reflected by the term $-\sigma_{j}^{2}$ in equation (1), and it explains the resolution of uncertainty around FOMC meetings. It also explains why SEP meetings had larger declines in uncertainty: Presumably the interest-rate jumps on these meetings had larger variance, since between January 2012 to December 2018 the FOMC only changed the policy rate at such meetings. A second reason for variation in uncertainty are changes in beliefs about future jump variances, captured by the last term in equation (1). If FOMC announcements provide information about the likely size of future short-rate jumps, this explains why $M P U$ exhibits substantial variation and is even sometimes positive. Consistent with this interpretation, we show below that the biggest changes in uncertainty occurred when the FOMC changed its forward guidance about future policy rates. In sum, the passing of the current FOMC jump explains the negative mean of has been lower since the FOMC started releasing the SEP. 
$M P U$, while changes in the beliefs about the likely size of future FOMC jumps explains the substantial variation in $M P U .{ }^{18}$

Many other types of news could affect short-rate uncertainty. Macroeconomic data releases are known to create substantial volatility in stock and bond markets (Andersen et al., 2007). However, $S R U$ declines only modestly on days with key macro announcements, such as the monthly employment report, and no macro release leads to a similarly large resolution of uncertainty as FOMC announcements, as documented in Appendix D.3. Other important news for financial markets include speeches by FOMC participants, which one might expect to potentially increase short-rate uncertainty due to the wide range of views expressed about the outlook for monetary policy, but Appendix D.4 shows that they have no systematic effect on $S R U$. Indeed, FOMC announcements appear unique in terms of their impact on short-rate uncertainty.

While short-rate uncertainty declines markedly on days with FOMC announcements, it tends to increase on non-FOMC days, as evident from the cumulative change reported in Table 2. Since the creation of uncertainty does not appear to be linked to macro announcements or other policy events, the question arises, when is uncertainty actually created? Figure 3 shows that after the initial drop around FOMC announcements, short-rate uncertainty tends to steadily increase over the first two weeks of the intermeeting period. This "FOMC uncertainty cycle" reveals that the average decline in short-rate uncertainty is transitory and soon reversed. ${ }^{19}$ Part of the explanation for the increase over the FOMC intermeeting period

\footnotetext{
${ }^{18}$ As shown in Appendix C, the average decline in the conditional variance around FOMC meetings implies a typical jump volatility around 8-19 bps, which is substantially larger than the historical volatility of interest rate changes on FOMC days, about 1.5 bps. This suggests that jump risk premia may play an important role to explain the resolution of uncertainty around FOMC announcements. Appendix C presents additional evidence that investors may indeed require compensation for the risk of FOMC jumps: A simple option trading strategy designed to benefit from falling uncertainty - short straddle positions around FOMC announcements - yields significantly positive returns. Despite some caveats to these specific results, such as the presence of transaction costs, the evidence on the whole appears consistent with the presence of significant FOMC jump risk premia.

${ }^{19}$ This pattern of short-rate uncertainty over the FOMC intermeeting period is much more pronounced than the pattern for the VIX. Appendix D.5 shows that the decline in $S R U$ on FOMC days is about twice as large as the decline in the VIX, and there is no clear ramp-up pattern in the VIX aside from a modest increase towards the day before the FOMC meeting. While further research is needed to pinpoint the exact reasons for these differences, a crucial distinction is that $S R U$ directly measures the uncertainty most directly affected by
} 
Figure 3: The FOMC uncertainty cycle

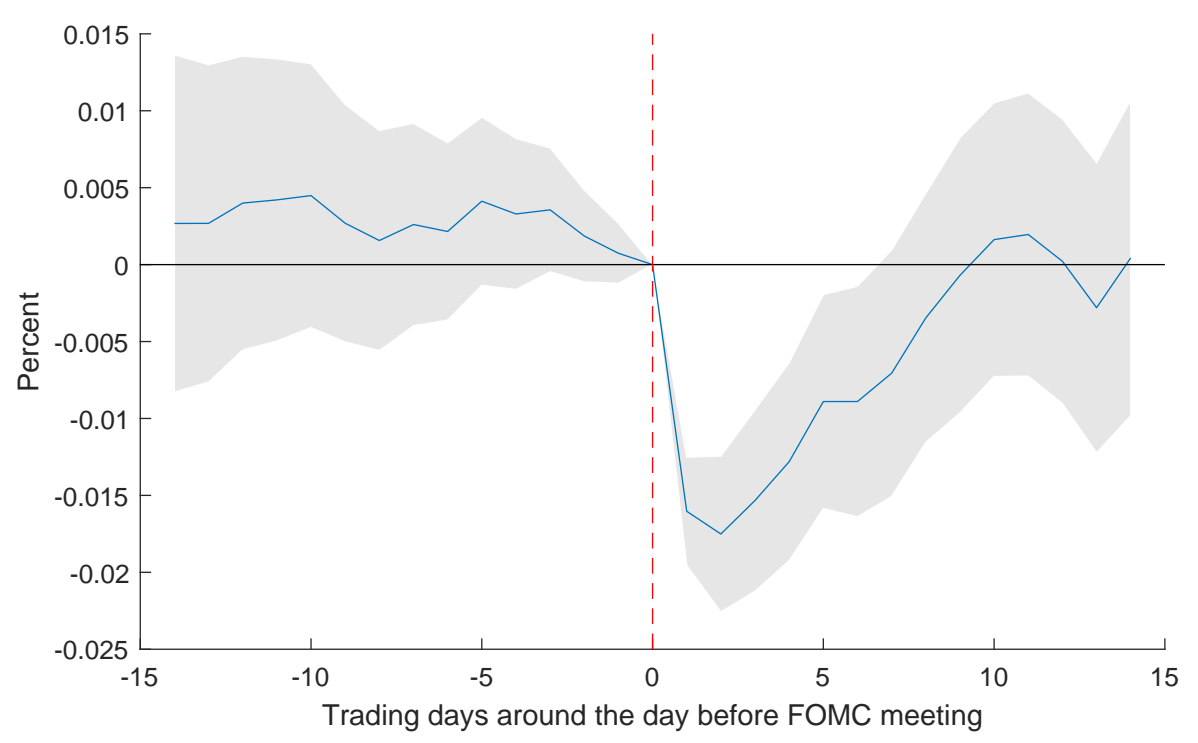

Changes in uncertainty over the FOMC meeting cycle: average change in one-year $S R U$ on trading days around scheduled FOMC announcements, relative to the day before the announcement (marked with a dashed red line), that is, sample mean of $S R U_{t+j-1}-S R U_{t-1}$ across all FOMC days $t$, for each value of $j$ ranging from -14 to +14 (since the average FOMC intermeeting period is about 30 trading days). Shaded areas show $95 \%$ confidence intervals based on White standard errors. Sample: 197 scheduled FOMC announcements from January 1994 to September 2020, excluding the period from July 2007 to June 2009 containing the Global Financial Crisis.

is mechanical: Right after an FOMC meeting, our interpolated one-year uncertainty measure contains fewer scheduled announcements within its horizon. According to our model, the measured uncertainty should then gradually move up as the average number of FOMC announcements within the next year increases. Interestingly, Figure 3 suggests that uncertainty ramps up only over the first two weeks after the announcement. Additional evidence in Appendix D.5 confirms that these two weeks are special and exhibit a significantly larger change in uncertainty than the rest of the intermeeting period. This quick ramp up in priced uncertainty, which is not explained by our simple jump model, is an intriguing characteristic of the FOMC uncertainty cycle.

How do actions taken by the FOMC affect monetary policy uncertainty? The substantial FOMC decisions, whereas stock market uncertainty is affected by many other factors. In addition, the shorter horizon and somewhat different methodology of the VIX (which uses option contracts of almost exactly 30 days maturity) may contribute to the differences. 
variation in $M P U$ evident in Figure 2 naturally raises this question. To answer it, we first investigate the relationship between $M P U$ and conventional measures of the first moment policy surprise arising from FOMC announcements. Then we zoom in on the largest changes in $M P U$ and uncover the drivers of these changes in the language of the actual FOMC statements.

Monetary policy surprises are typically measured as the changes in the expected policy rate path, using money market futures rates. We follow Nakamura and Steinsson (2018) and construct our monetary policy surprise, $M P S$, as the first principal component of rate changes based on fed funds and Eurodollar futures contracts expiring up to a year following the FOMC meeting. ${ }^{20}$ A regression of $M P U$ on $M P S$ reveals a moderate positive correlation between changes in perceived first and second moments of future short rates, with an $R^{2}$ of 0.27 and a positive slope coefficient that is highly statistically significant. This means that a more hawkish policy surprise - an increase in the expected rate path - is associated with a smaller than average decline or even an increase in uncertainty, and a dovish policy surprise is associated with a larger than average decline. ${ }^{21}$ There are two important implications: First, because of this correlation, estimates of the financial market impact of FOMC announcements should include not only the policy surprise measure, as is commonly done, but also changes in policy uncertainty. Otherwise such regressions may suffer from an omitted variable bias and incorrectly attribute some of the effects of $M P U$ on asset prices to $M P S$. Second, a substantial portion of the variation in $M P U$ is orthogonal to the first-moment surprise, which raises the possibility of a separate uncertainty channel for the monetary transmission. In Section 4 we will present results that separately account for both effects.

A narrative analysis of FOMC statements shows that the most pronounced impact of policy actions on uncertainty typically results from changes in the Fed's forward guidance.

\footnotetext{
${ }^{20}$ We use daily rate changes to be consistent with the daily changes in uncertainty. $M P S$ is scaled so that the effect on the four-quarters-ahead futures rate is equal to one.

${ }^{21}$ Details, including a scatter plot, are in Appendix D.2. There we also show results for alternative measures of the policy surprise, such as the target and path factors of Gürkaynak et al. (2005a). The positive correlation between $M P U$ and the policy surprises does not explain the negative mean of $M P U$, i.e., the resolution of uncertainty around FOMC meetings.
} 
Table 3: FOMC announcements and the largest changes in monetary policy uncertainty

\begin{tabular}{|c|c|c|c|}
\hline \multicolumn{4}{|r|}{ Top 10 declines in monetary policy uncertainty } \\
\hline Meeting date & $M P U$ & $M P S$ & Description \\
\hline 09 Aug 2011 & -0.137 & -0.032 & $\begin{array}{l}\text { Introduction of calendar-based forward guidance: "exceptionally low levels for } \\
\text { the federal funds rate at least through mid-2013." }\end{array}$ \\
\hline 16 Dec 2008 & -0.134 & -0.252 & $\begin{array}{l}\text { ZLB is reached and introduction of clear forward guidance phrase: "exception- } \\
\text { ally low levels of the federal funds rate for some time." }\end{array}$ \\
\hline 06 Jul 1995 & -0.129 & -0.213 & $\begin{array}{l}\text { First explicit mention of numerical target for federal funds rate. Also interest } \\
\text { rate cut: "...inflationary pressures have receded enough to accommodate a } \\
\text { modest adjustment in monetary conditions." }\end{array}$ \\
\hline 17 Nov 1998 & -0.123 & -0.032 & $\begin{array}{l}\text { Third cut in a row and signal that there may not be further cuts: "financial } \\
\text { conditions can reasonably be expected to be consistent with fostering sustained } \\
\text { economic expansion" }\end{array}$ \\
\hline 17 May 1994 & -0.101 & -0.140 & $\begin{array}{l}\text { Fed funds target rate increased by } 50 \text { bps to "...substantially remove the degree } \\
\text { of monetary accommodation which prevailed throughout 1993." }\end{array}$ \\
\hline 25 Nov 2008 & -0.096 & -0.156 & $\begin{array}{l}\text { TALF announcement: "... increase credit availability and support economic } \\
\text { activity by facilitating renewed issuance of consumer and small business ABS } \\
\text { at more normal interest rate spreads." }\end{array}$ \\
\hline 15 Oct 1998 & -0.083 & 0.085 & $\begin{array}{l}\text { FOMC stated that "further easing of the stance of monetary policy was judged } \\
\text { to be warranted to sustain economic growth" }\end{array}$ \\
\hline 18 Mar 2009 & -0.081 & -0.189 & $\begin{array}{l}\text { Change in language about low rates to "for an extended period" from previous } \\
\text { statement which said "for some time" }\end{array}$ \\
\hline $30 \mathrm{Ju}$ & -0.074 & -0.091 & First increase in four years and guidance about futu \\
\hline 29 Oct 2 & -0.074 & -0.108 & $\begin{array}{l}\text { Fed funds target rate cut by 50bps. Confirmation that the FOMC "...will act } \\
\text { as needed to promote sustainable economic growth and price stability." }\end{array}$ \\
\hline \multicolumn{4}{|r|}{ Top 5 increases in monetary policy uncertainty } \\
\hline Meeting Date & $M P U$ & $M P S$ & \\
\hline 08 Oct 2008 & 0.116 & -0.020 & $\begin{array}{l}\text { Announcement after unscheduled meeting of concerted actions by central banks } \\
\text { around the world }\end{array}$ \\
\hline 28 Jan 2004 & 0.052 & 0.115 & $\begin{array}{l}\text { Change in language to "... can be patient in removing its policy accommoda- } \\
\text { tion" and removal of "considerable period" language. }\end{array}$ \\
\hline 18 Apr 1994 & 0.038 & 0.207 & $\begin{array}{l}\text { Unscheduled conference call: "increase slightly the degree of pressure on reserve } \\
\text { positions. This action is expected to be associated with a small increase in } \\
\text { short-term money market interest rates." }\end{array}$ \\
\hline 04 Feb 1994 & 0.032 & 0.139 & $\begin{array}{l}\text { First rate hike in years in line with the FOMC decision "...to move toward a } \\
\text { less accommodative stance in monetary policy..." }\end{array}$ \\
\hline 28 Mar 1995 & 0.028 & 0.121 & $\begin{array}{l}\text { The FOMC indicated "asymmetric directive also would provide a clear signal } \\
\text { of the Committee's intention to resist higher inflation." }\end{array}$ \\
\hline
\end{tabular}

Ten largest declines and five largest increases in monetary policy uncertainty, $M P U$, along with the monetary policy surprise, $M P S$, and a brief narrative based on the FOMC statement.

Table 3 lists the most influential FOMC announcements: those ten with the biggest declines and those five with the biggest increases in uncertainty (also clearly visible in Figure 2). For each announcement, the table notes a key phrase or aspect of the FOMC statement and its role in the current monetary policy cycle. The first phase of explicit forward guidance 
began in 2003 when the FOMC under Alan Greenspan introduced the "considerable period" language at its May meeting to more clearly signal low future policy rates, which substantially reduced uncertainty. However, in January 2004 this language was replaced by a phrase "can be patient" which led to the second-largest increase in uncertainty in our sample. The second phase of explicit forward guidance began during the financial crisis and was marked by clearer messaging about the likely path for the future funds rate. It started with the "for some time" language introduced in December 2008, when the FOMC lowered the policy rate to essentially zero, coinciding with the second largest decline in uncertainty. The guidance was strengthened in March 2009 to "for an extended period" which also reduced uncertainty substantially. A third phase was the introduction of calendar-based guidance in August 2011 with the phrase "at least through mid-2013." This forward guidance dramatically reduced the uncertainty about liftoff and the future rate path, with the largest decrease in our sample.

Table 3 also shows that the effects on uncertainty are often quite distinct from those on the expected policy path. The positive correlation between $M P S$ and $M P U$ is evident in these announcements, but the correlation is far from perfect: The largest declines in uncertainty did not always coincide with large dovish surprises about the policy path, and vice versa. For example, among the four announcements with the largest declines in uncertainty, two of them (in July 1995 and December 2008) also led to substantial dovish surprises, whereas the other two (in August 2011 and November 1998) caused only modest first-moment policy surprises. The market change in forward guidance on August 9, 2011, is particularly noteworthy in this regard. Overall, our narrative evidence suggests that Fed communication has important effects on perceived monetary policy uncertainty, and that these changes in uncertainty are often a separate dimension of the Fed's policy actions. Through the lens of our jump model, the Fed's forward guidance changed investors' perceptions about future rate jumps and thus affected market-based uncertainty about future short rates. The next section will show the effects of such changes on asset prices. 


\section{Monetary policy transmission to asset prices}

Having established how short-rate uncertainty changes on FOMC announcement days and over the FOMC meeting cycle, we now investigate its role in the transmission of monetary policy to asset prices. We estimate the financial market effects of FOMC announcements using three different event-study regressions. A baseline regression estimates the response of asset prices to $M P S$, the market-based measure of the monetary policy surprise described in Section 3. A second regression adds the change in monetary policy uncertainty around the announcement, $M P U=\Delta S R U$, to estimate its effects on asset prices while controlling for its correlation with MPS. Finally, we further add an interaction effect between $M P S$ and the level of short-rate uncertainty on the day before the FOMC announcement, $S R U_{-1}$, to investigate whether the prevailing level of uncertainty affects the financial market response to policy surprises. ${ }^{22}$

The top panel of Table 4 reports estimates for changes in nominal and real Treasury yields. We use nominal yields from Gürkaynak et al. (2007) and TIPS yields from Gürkaynak et al. (2010) which start in February 1999. For nominal yields the first specification confirms the well-established result that policy surprises have sizeable and significant effects (Gürkaynak et al., 2005a). The second regression shows a statistically significant and positive response of yields to $M P U$, in addition to the well-known effects of the policy surprise. A one standard deviation increase in uncertainty raises the five- and ten-year nominal yields by around 2 bps. Real yields also exhibit strong responses to policy surprises, in line with the findings by Hanson and Stein (2015) and Nakamura and Steinsson (2018). Uncertainty has statistically significant effects on real yields that are similar in magnitude to its effects on nominal yields. ${ }^{23}$

\footnotetext{
${ }^{22}$ Our sample of FOMC announcements was described in Section 3. To economize on space in our tables, we do not report the estimated regression intercept, or the coefficient on the lagged level of uncertainty that is included in the third regression specification to accurately estimate the interaction effect.

${ }^{23}$ These estimates suggest that effects of changes in policy uncertainty around the notable FOMC announcements highlighted in Table 3 are sizeable. For example, on August 11, 2011 uncertainty dropped by 13.7 bps, and our estimates indicate that roughly half the actual decline of 20 bps in the nominal and 18 bps in the real 10 year Treasury yield on that day is attributable to $M P U$.
} 
Table 4: Transmission of monetary policy uncertainty to financial markets

\begin{tabular}{|c|c|c|c|c|c|c|c|c|c|}
\hline \multirow[b]{2}{*}{$M P S$} & \multicolumn{3}{|c|}{ 5y nominal yield } & \multicolumn{3}{|c|}{ 10y nominal yield } & \multicolumn{3}{|c|}{ 10y TIPS yield } \\
\hline & $\begin{array}{c}0.65 \\
{[8.64]}\end{array}$ & $\begin{array}{c}0.53 \\
{[6.33]}\end{array}$ & $\begin{array}{c}1.26 \\
{[6.51]}\end{array}$ & $\begin{array}{c}0.46 \\
{[7.42]}\end{array}$ & $\begin{array}{c}0.32 \\
{[4.78]}\end{array}$ & $\begin{array}{c}0.74 \\
{[4.42]}\end{array}$ & $\begin{array}{c}0.44 \\
{[6.06]}\end{array}$ & $\begin{array}{c}0.33 \\
{[4.35]}\end{array}$ & $\begin{array}{c}1.25 \\
{[3.57]}\end{array}$ \\
\hline$M P U$ & & $\begin{array}{c}0.60 \\
{[2.76]}\end{array}$ & $\begin{array}{c}0.81 \\
{[3.49]}\end{array}$ & & $\begin{array}{c}0.68 \\
{[2.82]}\end{array}$ & $\begin{array}{c}0.86 \\
{[3.33]}\end{array}$ & & $\begin{array}{c}0.72 \\
{[3.13]}\end{array}$ & $\begin{array}{c}0.88 \\
{[3.62]}\end{array}$ \\
\hline$M P S \times S R U_{-1}$ & & & $\begin{array}{c}-0.66 \\
{[-3.54]}\end{array}$ & & & $\begin{array}{l}-0.38 \\
{[-2.33]}\end{array}$ & & & $\begin{array}{l}-0.97 \\
{[-2.68]}\end{array}$ \\
\hline \multirow[t]{2}{*}{$R^{2}$} & 0.46 & 0.51 & 0.57 & 0.27 & 0.34 & 0.38 & 0.20 & 0.26 & 0.36 \\
\hline & \multicolumn{3}{|c|}{ S\&P 500} & \multicolumn{3}{|c|}{ VIX } & \multicolumn{3}{|c|}{ Dollar index } \\
\hline$M P S$ & $\begin{array}{c}-3.31 \\
{[-3.32]}\end{array}$ & $\begin{array}{c}-1.60 \\
{[-1.26]}\end{array}$ & $\begin{array}{l}-11.22 \\
{[-3.13]}\end{array}$ & $\begin{array}{c}4.07 \\
{[2.83]}\end{array}$ & $\begin{array}{c}-0.28 \\
{[-0.12]}\end{array}$ & $\begin{array}{l}16.95 \\
{[2.99]}\end{array}$ & $\begin{array}{c}2.40 \\
{[3.62]}\end{array}$ & $\begin{array}{c}1.52 \\
{[2.14]}\end{array}$ & $\begin{array}{l}12.25 \\
{[3.93]}\end{array}$ \\
\hline$M P U$ & & $\begin{array}{l}-8.66 \\
{[-1.75]}\end{array}$ & $\begin{array}{l}-10.88 \\
{[-2.16]}\end{array}$ & & $\begin{array}{l}22.06 \\
{[1.73]}\end{array}$ & $\begin{array}{l}26.60 \\
{[1.95]}\end{array}$ & & $\begin{array}{c}4.30 \\
{[2.22]}\end{array}$ & $\begin{array}{c}6.20 \\
{[3.98]}\end{array}$ \\
\hline$M P U \times S R U_{-1}$ & & & $\begin{array}{l}8.73 \\
{[2.82]}\end{array}$ & & & $\begin{array}{l}-15.63 \\
{[-2.75]}\end{array}$ & & & $\begin{array}{c}-9.52 \\
{[-4.04]}\end{array}$ \\
\hline$R^{2}$ & 0.05 & 0.09 & 0.13 & 0.04 & 0.14 & 0.21 & 0.10 & 0.14 & 0.32 \\
\hline
\end{tabular}

Event-study regressions for FOMC announcemente of changes in asset prices on a monetary policy surprise $(M P S)$, the change in policy uncertainty $(M P U)$, and an interaction of $M P S$ with the ex-ante level of shortrate uncertainty $\left(S R U_{-1}\right)$. The third specification also includes $S R U_{-1}$ but the coefficient is omitted, as are all regression intercepts, to economize on space. Dependent variables are daily changes in yields, daily returns in the S\&P500 index, changes in the VIX, and returns on a foreign currency portfolio short G9 currencies and long the dollar. White heteroscedasticity-robust $t$-statistics are in brackets. Sample: 197 scheduled FOMC announcements from January 1994 to September 2020, excluding the period from July 2007 to June 2009 containing the Global Financial Crisis, except that the sample for TIPS yields starts in September 1999, and the sample for the dollar index ends in June 2020.

Changes in monetary policy uncertainty also matter for other asset prices, as shown in the bottom panel of Table 4. Stock prices tend to fall not only in response to hawkish policy surprises, but also when short-rate uncertainty increases. ${ }^{24} \mathrm{~A}$ one standard deviation increase in uncertainty reduces stock prices by $0.3 \%$. Similarly, the VIX and thus stock market volatility tends to increase not only with a hawkish policy surprise but also with rising policy uncertainty. A one standard deviation increase in uncertainty increases the VIX by 0.7 percentage points. Changes in monetary policy uncertainty appear to be an important driver of the stock market around FOMC announcements. Finally we consider the transmission of uncertainty to the

\footnotetext{
${ }^{24}$ In our baseline regression the stock market response to MPS is a little smaller relative to Bernanke and Kuttner (2005) and Gürkaynak et al. (2005a), mainly because of our use of a daily window to construct MPS. Using an intra-day policy surprise yields larger estimates of the effects on stock prices, as noted in Lakdawala and Schaffer (2019).
} 
foreign exchange market, using a US dollar index based on a foreign exchange portfolio that goes short the G9 currencies and long the US dollar. ${ }^{25}$ Due to data availability, the sample for the exchange rate regression ends in June 2020. A contractionary policy surprise leads to an appreciation of the dollar, consistent with the notion that tighter Fed policy make dollar fixed income investments more attractive and increase demand for the US dollar. Again, the table shows a statistically significant and economically meaningful additional impact of $M P U$. A one standard deviation rise in uncertainty leads to an appreciation of the US Dollar index by $0.16 \%$.

Regressions that include both $M P S$ and $M P U$ show clear evidence for an uncertainty channel of the transmission of FOMC actions to financial markets. Interestingly, they estimate a smaller effect of $M P S$ than a univariate regression does. This suggests that part of the large previously estimated effects of policy surprises on yields and asset prices may be due to the impact of policy uncertainty, which is omitted in the commonly used univariate regressions. Since conventional policy surprises are positively correlated with changes in uncertainty, omitting $M P U$ from event-study regressions attributes its asset price effects to $M P S$ and may lead to an upward bias in the estimated impact of the policy surprise. Once we control for changes in uncertainty, these estimated responses decline.

Estimates for our third specification reveal that for all yields and asset prices, the magnitude of the response to policy surprises depends on the level of short-rate uncertainty on the day before the FOMC announcement $\left(S R U_{-1}\right)$ : The response to $M P S$ is generally more muted when uncertainty is high. For yields, the interaction coefficients are negative, meaning that the positive impact of $M P S$ on yields is stronger when uncertainty is low. To gauge the magnitude of the effect, we use the $25^{\text {th }}$ and $75^{\text {th }}$ percentiles of $S R U$ to classify "low" and "high" uncertainty periods. In response to a 100 basis point contractionary monetary policy surprise, the five-year (ten-year) nominal yield increases by 91 (54) bps when uncertainty is

\footnotetext{
${ }^{25}$ The return to the dollar index is constructed by forming an equal weighted portfolio of the Australian dollar, the Canadian dollar, the British pound, the euro, the Japanese yen, the New Zealand dollar, the Norwegian krone, the Swedish krona and the Swiss franc, as in Lustig et al. (2011).
} 
low but only by 54 (33) bps when uncertainty is high. The dependence of the real yield response on uncertainty is even more pronounced. The ten-year real yield increases by 74 bps when uncertainty is low but only by 19 bps when uncertainty is high. A similar calculation for the S\&P 500 shows that a 100 bps hakwkish surprise, stock prices fall $6.6 \%$ when uncertainty is low but only by $1.7 \%$ when uncertainty is high.

These findings are robust across a variety of different empirical specifications. Neither the inclusion of unscheduled announcements and those during the financial crisis period, nor different choices of the monetary policy surprise - using for example higher-frequency (30minute window) or lower-frequency (2-day window) changes - has any material impact on our results (results omitted). Appendix E reports two additional sets of robustness checks: Estimates for nominal and real forward rates, using the empirical approach of Hanson and Stein (2015), show similar results to those reported above both for the effect of changes in uncertainty and the interaction effects. And regressions that replace $M P S$ with the target and path facts of Gürkaynak et al. (2005a), who showed that two separate factors are useful for accurately characterizing monetary policy surprises, also lead to similar results. This last result implies that even when controlling for the policy surprise, i.e., for shifts in first moments, in this more flexible two-dimensional way, there is a clear separate role for second moments in the transmission of policy actions to financial markets.

Our analysis has shown that the uncertainty channel has been an important part of monetary policy actions taken by the Federal Reserve over about the last quarter century. Most of these were conventional policy actions. Appendix F presents additional results for an event study of specific announcements of unconventional monetary policies, such as balance sheet policies and forward guidance. Such announcements had substantial effects on perceived monetary policy uncertainty, which increased the effectiveness of forward guidance and of the signaling channel of asset purchases (Bauer and Rudebusch, 2014). Overall, the uncertainty channel also appears to significantly contribute to the financial market effects of unconventional monetary policy. 
We have documented two channels through which uncertainty matters for monetary transmission to financial markets, related to (i) changes in uncertainty due to FOMC announcement, and (ii) the prevailing level of uncertainty before the FOMC announcement. While a full theoretical account of the empirical findings is beyond the scope of our paper, we suggest a plausible explanation for each one.

A simple risk-based explanation can provide a rationale for the negative effects of higher uncertainty on bond prices, stock prices, and the value of foreign currencies vis-a-vis the dollar. Standard asset pricing theory implies that expected excess returns depend on the negative covariance of returns with the stochastic discount factor (SDF). As pointed out by Hanson and Stein (2015), the factors driving this covariance are the uncertainty about future returns, the uncertainty about the SDF, and the correlation. Our results are consistent with effects of higher uncertainty on risk premia: If higher short-rate uncertainty coincides with higher uncertainty about the returns of the above-mentioned asset classes, then this raises expected excess returns/risk premia and lowers asset prices. ${ }^{26}$ Evidence that supports this risk-based explanation comes from estimated risk premiums: Appendix E shows that estimates of the term premium exhibit a strong positive response to $M P U{ }^{27}$ Given the uncertainty in estimated risk premiums this evidence is only suggestive, but it supports the view that the effects of monetary policy uncertainty on asset prices are partly due to changes in risk premia.

This risk-based explanation has implications for how we should interpret the large effects of monetary policy surprises on asset prices that previous studies have estimated (Gürkaynak

\footnotetext{
${ }^{26}$ Specifically, for gross return $R_{t+1}$, risk-free rate $R_{t}^{f}$, and SDF $M_{t+1}$, absence of arbitrage implies

$$
E_{t} R_{t+1}-R_{t}^{f}=-\operatorname{Cov}_{t}\left(M_{t+1}, R_{t+1}\right) / E_{t} M_{t+1} .
$$

The risk premium increases and the current asset price declines if the covariance between $M_{t+1}$ and $R_{t+1}$ becomes more negative, which could arise due to (a) higher $\sigma_{t}\left(R_{t+1}\right)$, (b) higher $\sigma_{t}\left(M_{t+1}\right)$, (c) a more negative correlation, or a combination of these factors. If higher $S R U$ coincides with higher conditional return volatility $\sigma_{t}\left(R_{t+1}\right)$ then asset prices will fall. Another risk-based channel could work through higher $\sigma_{t}\left(M_{t+1}\right)$, which would simultaneously raise both the variance risk premia inherent in our $S R U$ measure as well as the risk premia in all other financial assets.

${ }^{27}$ These findings are consistent with those of Bundick et al. (2017), althought we use a different empirical framework. In particular, we control for changes in the expected policy path, measured by MPS, which is important because of the correlation with $M P U$.
} 
et al., 2005b; Bernanke and Kuttner, 2005; Hanson and Stein, 2015; Nakamura and Steinsson, 2018). A portion of these large estimated effects appears to be due to a positive correlation with changes in uncertainty and risk premia. Hanson and Stein (2015) questioned that policy surprises increase term premia by changing uncertainty, stating that "little evidence exists for it in the data" (p. 442). But we have provided exactly this evidence, by documenting the positive correlation between $M P S$ and $M P U$, as well as the effects on risk premiums. The effects of monetary policy uncertainty can provide an explanation for the puzzle why policy surprises cause such large swings in asset prices.

The second channel we document is that high uncertainty mutes the effects of a monetary policy surprise on asset prices, while low uncertainty leads to a significantly stronger impact. This result can be rationalized using the logic of signal extraction (for a formal argument, see Appendix G). Market participants form their forecasts of future asset prices and fundamentals based on a variety of signals, including signals from the Fed about the expected path of future policy rates. Under general conditions, the weight put on the signal from the Fed increases in the precision of that signal. Thus when uncertainty is low (precision of the signal is high), market participants will revise their forecasts more in response to the information in the public signal (i.e. policy surprise). Vice versa, in the presence of high uncertainty, signals from the Fed are less precise and thus elicit a more muted reaction of asset prices. $^{28}$

\section{Conclusion}

While the macro-finance literature has mainly studied the effects of changes in the first moment of the distribution of the future policy rate, this paper provides new evidence that the second moment of this distribution also plays an important role for the transmission of monetary

\footnotetext{
${ }^{28}$ De Pooter et al. (2021) also show that monetary policy surprises have stronger effects on Treasury yields when uncertainty is low. They propose a very different explanation that relies on institutional features of the Treasury market: Primary dealers appear to behave differently during times when uncertainty is low, and this behavior might amplify the impact of policy surprises on Treasury yields. Our signal-extraction argument, by contrast, can explain the broader findings beyond Treasury markets that we document in Table 4.
} 
policy to financial markets. FOMC announcements have substantial effects on uncertainty: On average, we observe a systematic resolution of uncertainty that is most drastic for announcements of forward guidance. In addition, monetary policy uncertainty matters for the transmission of policy actions to financial markets in two ways: First, changes in uncertainty about the policy rate have strong additional effects on a variety of asset prices, even after controlling for changes in the expected policy rate path. Second, the level of uncertainty leading up to a FOMC announcement is critical in determining how policy surprises are transmitted to financial markets. Specifically, policy surprises have larger effects on asset prices when monetary policy uncertainty is lower. Taken together, this evidence indicates the presence of an uncertainty channel for the transmission of monetary policy to financial markets.

Our paper points to several fruitful directions for future research. What are the respective roles of macroeconomic and policy uncertainty for the overall level of uncertainty about future interest rates? A meaningful decomposition using structural models with time-varying uncertainty would likely yield important new insights. What type of central bank communications and policy actions are most effective in lowering policy uncertainty? The use of novel tools of textual analysis and natural language processing appears particularly promising to address this question. And what are the macroeconomic effects of changes in monetary policy uncertainty? Some recent studies have taken important first steps in this direction, including Husted et al. (2020) and Bundick et al. (2017). However, much work remains to be done to make full use of high-frequency, market-based uncertainty measures to identify the causal effects of changes in monetary policy uncertainty on macroeconomic variables.

\section{References}

Aastveit, Knut Are, Gisle James Natvik, and Sergio Sola (2017) "Economic uncertainty and the influence of monetary policy," Journal of International Money and Finance, Vol. 76, pp. 50-67.

Adrian, Tobias, Richard Crump, and Emanuel Moench (2013) "Pricing the Term Structure with Linear Regressions," Journal of Financial Economics, Vol. 110, pp. 110-138. 
Amengual, Dante and Dacheng Xiu (2018) "Resolution of Policy Uncertainty and Sudden Declines in Volatility," Journal of Econometrics, Vol. 203, pp. 297-315.

Andersen, Torben G, Tim Bollerslev, Francis X Diebold, and Clara Vega (2007) "Real-time price discovery in global stock, bond and foreign exchange markets," Journal of International Economics, Vol. 73, pp. 251-277.

Andrade, Philippe and Filippo Ferroni (2020) "Delphic and Odyssean monetary policy shocks: Evidence from the euro area," Journal of Monetary Economics.

Baker, Scott R., Nicholas Bloom, and Steven J. Davis (2016) "Measuring Economic Policy Uncertainty," Quarterly Journal of Economics, Vol. 131, pp. 1593-1636.

Bauer, Michael D. (2015) "Nominal Interest Rates and the News," Journal of Money, Credit and Banking, Vol. 47, pp. 295-332.

Bauer, Michael D. and Christopher J. Neely (2014) "International Channels of the Fed's Unconventional Monetary Policy," Journal of International Money and Finance, Vol. 44, pp. 24-46.

Bauer, Michael D. and Glenn D. Rudebusch (2014) "The Signaling Channel for Federal Reserve Bond Purchases," International Journal of Central Banking, Vol. 10, pp. 233-289.

Bauer, Michael D. and Eric T. Swanson (2020) "The Fed's Response to Economic News Explains the "Fed Information Effect"," Working Paper w27013, National Bureau of Economic Research.

Beber, A. and M. W. Brandt (2006) "The Effect of Macroeconomic News on Beliefs and Preferences: Evidence from the Options Market," Journal of Monetary Economics, Vol. 53, pp. 1997-2039.

Bekaert, Geert, Marie Hoerova, and Marco Lo Duca (2013) "Risk, Uncertainty and Monetary Policy," Journal of Monetary Economics, Vol. 60, pp. 771-788.

Benamar, Hedi, Thierry Foucault, and Clara Vega (2020) "Demand for Information, Uncertainty, and the Response of US Treasury Securities to News," forthcoming, Review of Financial Studies.

Bernanke, Ben S. and Kenneth N. Kuttner (2005) "What explains the stock market's reaction to Federal Reserve policy?" Journal of Finance, Vol. 60, pp. 1221-1257.

Bikbov, Ruslan and Mikhail Chernov (2009) "Unspanned stochastic volatility in affine models: evidence from eurodollar futures and options," Management Science, Vol. 55, pp. 1292-1305.

Black, Fisher (1976) "The Pricing of Commodity Contracts," Journal of Financial Economics, Vol. 3, pp. 167-179. 
Boguth, Oliver, Vincent Grégoire, and Charles Martineau (2019) "Shaping Expectations and Coordinating Attention: The Unintended Consequences of FOMC Press Conferences," Journal of Financial and Quantitative Analysis, Vol. 54, pp. 2327-2353.

Britten-Jones, Mark and Anthony Neuberger (2000) "Option Prices, Implied Price Processes, and Stochastic Volatility," Journal of Finance, Vol. 55, pp. 839-866.

Bundick, Brent and Trenton Herriford (2017) "How Do FOMC Projections Affect Policy Uncertainty?" Economic Review, Vol. 102, pp. 5-23.

Bundick, Brent, Trenton Herriford, and A. Lee Smith (2017) "Forward Guidance, Monetary Policy Uncertainty, and the Term Premium," Working Paper, Federal Reserve Bank of City.

Cascaldi-Garcia, Danilo, Cisil Sarisoy, Juan M. Londono, John Rogers, Deepa Datta, Thiago Ferreira, Olesya Grishchenko, Mohammad R. Jahan-Parvar, Francesca Loria, Sai Ma, Marius Rodriguez, , and Ilknur Zer (2020) "What is Certain about Uncertainty?" International Finance Discussion Papers 1294, Federal Reserve Board of Governors.

Chan, K. C., G. Andrew Karolyi, Francis A. Longstaff, and Anthony B. Sanders (1992) "An Empirical Comparison of Alternative Models of the Short-Term Interest Rate," Journal of Finance, Vol. 47, pp. 1209-1227.

Chang, Bo Young and Bruno Feunou (2013) "Measuring Uncertainty in Monetary Policy Using Implied Volatility and Realized Volatility," Bank of Canada Working Paper No. 2013-37.

Chatterjee, Indradeap, Marina Di Giacinto, and Claudio Tebaldi (2020) "Impact of FOMC Cycle on Market Uncertainty: Evidence From Interest Rate Derivatives," August, working paper.

Choi, Hoyong, Philippe Mueller, and Andrea Vedolin (2017) "Bond Variance Risk Premiums," Review of Finance, Vol. 21, pp. 987-1022.

Cook, Timothy and Thomas Hahn (1989) "The Effect of Changes in the Federal Funds Rate Target on Market Interest Rates in the 1970s," Journal of Monetary Economics, Vol. 24, pp. 331-351.

Creal, Drew D. and Jing Cynthia Wu (2017) "Monetary policy uncertainty and economic fluctuations," International Economic Review, Vol. 58, pp. 1317-1354.

De Pooter, Michiel, Giovanni Favara, Michele Modugno, and Jason Wu (2021) "Monetary policy uncertainty and monetary policy surprises," Journal of International Money and Finance, Vol. 112.

Dubinsky, Andrew, Michael Johannes, Andreas Kaeck, and Norman J Seeger (2018) "Option pricing of earnings announcement risks," Review of Financial Studies, Vol. 32, pp. 646-687.

Ederington, Louis H. and Jae Ha Lee (1996) "The Creation and Resolution of Market Uncertainty: The Impact of Information Releases on Implied Volatility," Journal of Financial and Quantitative Analysis, Vol. 31, pp. 513-539. 
Emmons, William R., Aeimit K. Lakdawala, and Christopher J. Neely (2006) "What are the odds? Option-based forecasts of FOMC target changes," Federal Reserve Bank of St. Louis Review, Vol. 88, pp. 543-561.

Fernandez-Perez, Adrian, Bart Frijns, and Alireza Tourani-Rad (2017) "When no news is good news-The decrease in investor fear after the FOMC announcement," Journal of Empirical Finance, Vol. 41, pp. 187-199.

Fernández-Villaverde, Jesús, Pablo Guerrón-Quintana, Keith Kuester, and Juan RubioRamírez (2015) "Fiscal volatility shocks and economic activity," American Economic Review, Vol. 105, pp. 3352-84.

Gagnon, Joseph, Matthew Raskin, Julie Remache, and Brian P. Sack (2011) "The Financial Market Effects of the Federal Reserve's Large-Scale Asset Purchases," International Journal of Central Banking, Vol. 7, pp. 3-43.

$\mathrm{Gu}$, Chen, Alexander Kurov, and Marketa Halova Wolfe (2018) "Relief Rallies after FOMC Announcements as a Resolution of Uncertainty," Journal of Empirical Finance, Vol. 49, pp. $1-18$.

Gürkaynak, Refet S., Brian P. Sack, and Eric T. Swanson (2005a) "Do Actions Speak Louder Than Words? The Response of Asset Prices to Monetary Policy Actions and Statements," International Journal of Central Banking, Vol. 1.

Gürkaynak, Refet S., Brian P. Sack, and Eric T. Swanson (2005b) "The Sensitivity of LongTerm Interest Rates to Economic News: Evidence and Implications for Macroeconomic Models," American Economic Review, Vol. 95, pp. 425-436.

Gürkaynak, Refet S., Brian P. Sack, and Jonathan H. Wright (2007) "The U.S. Treasury Yield Curve: 1961 to the Present," Journal of Monetary Economics, Vol. 54, pp. 2291-2304.

Gürkaynak, Refet S., Brian P. Sack, and Jonathan H. Wright (2010) "The TIPS Yield Curve and Inflation Compensation," American Economic Journal: Macroeconomics, Vol. 2, pp. 70-92.

Hanson, Samuel G. and Jeremy C. Stein (2015) "Monetary Policy and Long-Term Real Rates," Journal of Financial Economics, Vol. 115, pp. 429-448.

Hu, Grace Xing, Jun Pan, Jiang Wang, and Haoxiang Zhu (2019) "Premium for Heightened Uncertainty: Solving the FOMC Puzzle," July, NBER Working Paper No. 25817.

Husted, Lucas, John Rogers, and Bo Sun (2020) "Monetary Policy Uncertainty," Journal of Monetary Economics, Vol. 115, pp. 20-36.

Jiang, George and Yisong Tian (2005) "Model-Free Implied Volatility and Its Information Content," Review of Financial Studies, Vol. 18, pp. 1305-1342.

Johannes, Michael (2004) "The statistical and economic role of jumps in continuous-time interest rate models," The Journal of Finance, Vol. 59, pp. 227-260. 
Jurado, Kyle, Sidney C. Ludvigson, and Serena Ng (2015) "Measuring Uncertainty," American Economic Review, Vol. 105, pp. 1177-1216.

Kim, Don H. and Jonathan H. Wright (2005) "An Arbitrage-Free Three-Factor Term Structure Model and the Recent Behavior of Long-Term Yields and Distant-Horizon Forward Rates," Finance and Economics Discussion Series 2005-33, Board of Governors of the Federal Reserve System.

Kim, Don H. and Jonathan H. Wright (2014) "Jumps in bond yields at known times," Working Paper 20711, National Bureau of Economic Research.

Krishnamurthy, Arvind and Annette Vissing-Jorgensen (2011) "The Effects of Quantitative Easing on Interest Rates: Channels and Implications for Policy," Brookings Papers on Economic Activity, pp. 215-265.

Kroencke, Tim, Maik Schmeling, and Andreas Schrimpf (2019) "The FOMC Risk Shift," CEPR Discussion Papers 14037, C.E.P.R. Discussion Papers.

Kuttner, Kenneth N. (2001) "Monetary policy surprises and interest rates: Evidence from the Fed funds futures market," Journal of Monetary Economics, Vol. 47, pp. 523-544.

Kuttner, Kenneth N. (2018) "Outside the box: unconventional monetary policy in the Great Recession and beyond," Journal of Economic Perspectives, Vol. 32, pp. 121-46.

Lakdawala, Aeimit, Timothy Moreland, and Matthew Schaffer (2020) "The International Spillover Effects of US Monetary Policy Uncertainty," Working Paper, https://dx.doi.org/10.2139/ssrn.3580933.

Lakdawala, Aeimit and Matthew Schaffer (2019) "Federal Reserve Private Information and the Stock Market," Journal of Banking and Finance, Vol. 106, pp. 34-49.

Lucca, David O. and Emanuel Moench (2015) "The Pre-FOMC Announcement Drift," Journal of Finance, Vol. 70, pp. 329-371.

Lustig, Hanno, Nikolai Roussanov, and Adrien Verdelhan (2011) "Common Risk Factors in Currency Markets," Review of Financial Studies, Vol. 24, pp. 3731-3777.

Mueller, Philippe, Alireza Tahbaz-Salehi, and Andrea Vedolin (2017) "Exchange Rates and Monetary Policy Uncertainty," Journal of Finance, Vol. 72, pp. 1213-1252.

Muravyev, Dmitriy and Neil D. Pearson (2020) "Options trading costs are lower than you think," The Review of Financial Studies, Vol. 33, pp. 4973-5014.

Nakamura, Emi and Jón Steinsson (2018) "High-Frequency Identification of Monetary NonNeutrality: The Information Effect," Quarterly Journal of Economics, Vol. 133, pp. 12831330 .

Neely, Christopher (2005) "Using Implied Volatility to Measure UncertaintyAbout Interest Rates," Federal Reserve Bank of St. Louis Review, Vol. 87(3), pp. 407-425. 
Piazzesi, Monika (2001) "An econometric model of the yield curve with macroeconomic jump effects," Working Paper 8246, National Bureau of Economic Research.

Rogers, John H. and Jiawen Xu (2019) "How Well Does Economic Uncertainty Forecast Economic Activity?" FEDS Working Paper 2019-085, Federal Reserve Board of Governors.

Swanson, Eric T. (2006) "Have increases in Federal Reserve transparency improved private sector interest rate forecasts?" Journal of Money, Credit, and banking, Vol. 38, pp. 791-819.

Swanson, Eric T. (2020) "Measuring the effects of Federal Reserve forward guidance and asset purchases on financial markets," forthcoming, Journal of Monetary Economics.

Swanson, Eric T. and John C. Williams (2014) "Measuring the effect of the zero lower bound on medium-and longer-term interest rates," American Economic Review, Vol. 104, pp. 315485 .

Tillmann, Peter (2020) "Monetary Policy Uncertainty and the Response of the Yield Curve to Policy Shocks," Journal of Money, Credit and Banking, Vol. 52, pp. 803-833.

Trolle, Anders B. and Eduardo S. Schwartz (2014) "The Swaption Cube," Review of Financial Studies, Vol. 27, pp. 2307-2353. 


\section{Online Appendix}

\section{A Measuring short-rate uncertainty}

\section{A.1 Details of $S R U$ calculation}

Denoting by $F_{t, T}$ the time- $t$ value of a Eurodollar futures contract expiring at $T$, the value at expiration is $F_{T, T}=100-L_{T}$, where $L_{T}$ is LIBOR in percent. Tied to each futures contract are option contracts, with payoff $\max \left(F_{T, T}-K, 0\right)$ for call options and $\max \left(K-F_{T, T}, 0\right)$ for put options, where $K$ is the strike price. These Eurodollar options are effectively options on LIBOR. For a given trading date $t$ and an expiration date $T$, one can use the prices of call options, $c_{t, T}(K)$, and put options, $p_{t, T}(K)$ to calculate the market-based conditional variance of future LIBOR, $\operatorname{Var}_{t}\left(L_{T}\right)$. This appendix derives an expression for $\operatorname{Var}_{t}\left(L_{t}\right)$ and then explains the semiparametric method we use to empirically implement this measure.

The option-implied variance $\operatorname{Var}_{t}\left(L_{T}\right)$ is taken under the so-called $T$-forward measure, under which a time- $T$ bond is the numeraire. To ease notation we omit a superscript such as $\mathbb{Q}_{T}$ with the expectations and variance operators. Under this measure the price $p_{t}$ of a future payoff $x_{T}$ is $p_{t}=P_{t, T} E_{t}\left(x_{T}\right)$, where $P_{t, T}$ is the price of a zero-coupon bond maturing at $T$. This measure is similar to the familiar "risk-neutral" measure, in that both reflect probabilities implied by market prices; under deterministic interest rates both measures would be identical, but the $T$-forward measure is more convenient for option pricing in the case of stochastic interest rates.

We now derive an expression relating conditional variance to market prices:

$$
\begin{aligned}
\operatorname{Var}_{t}\left(L_{T}\right) & =\operatorname{Var}_{t}\left(F_{T, T}\right)=E_{t} F_{T, T}^{2}-\left(E_{t} F_{T, T}\right)^{2}=E_{t} F_{T, T}^{2}-F_{t, T}^{2} \\
& =\frac{2}{P_{t, T}} \int_{0}^{\infty} c_{t, T}(K) d K-F_{t, T}^{2} \\
& =\frac{2}{P_{t, T}}\left(\int_{0}^{F_{t, T}} p_{t, T}(K)+P_{t, T}\left(F_{t, T}-K\right) d K+\int_{F_{t, T}}^{\infty} c_{t, T}(K) d K\right)-F_{t, T}^{2} \\
& =\frac{2}{P_{t, T}}\left(\int_{0}^{F_{t, T}} p_{t, T}(K)+\int_{F_{t, T}}^{\infty} c_{t, T}(K) d K\right) \\
& =2 \int_{0}^{\infty}\left[\frac{c_{t, T}(K)}{P_{t, T}}-\max \left(0, F_{t, T}-K\right)\right] d K .
\end{aligned}
$$

The last equality in the first line follows from the fact that any forward price is a martingale under the forward- $T$ measure. ${ }^{29}$ To obtain the second line we use the fact that $x^{2}=2 \int_{0}^{\infty} \max (0, x-K) d K$ for any $x \geq 0$, so that $E_{t} F_{T, T}^{2}=2 \int_{0}^{\infty} E_{t} \max \left(0, F_{T, T}-K\right) d K=$ $\frac{2}{P_{t, T}} \int_{0}^{\infty} c_{t, T}(K) d K$. The third line uses put-call-parity $c_{t, T}(K)-p_{t, T}(K)=P_{t, T}\left(F_{t, T}-K\right)$.

Expression A.2 shows that the conditional variance of future LIBOR can be written as a

\footnotetext{
${ }^{29}$ Here we treat $F_{t, T}$ as a forward price, although Eurodollar futures have daily settlement and $F_{t, T}$ is a futures price (and thus a martingale only under the risk-neutral measure).
} 
portfolio of out-of-the-money Eurodollar puts and calls, and it is similar to the well-known formula for the fair strike of a variance swap (e.g., equation (6) in Choi et al., 2017). Expression A.3 is useful for implementation, and it resembles the formula for model-free implied volatility of Britten-Jones and Neuberger (2000) and Jiang and Tian (2005). The difference with those existing results is that we focus on the variance of the level, whereas those formulas apply to the variance of logs/returns. ${ }^{30}$

We abstract from the fact that Eurodollar options are American options on futures contracts, and not, as our derivations assume, European options on forward contracts. Existing results suggest that accounting for early exercise would lead to only minor adjustments; see Bikbov and Chernov (2009) and Choi et al. (2017). In addition, since we only use out-ofthe-money options any adjustment for early exercise would be minimal, since there are no dividends and the early-exercise premium increases with the moneyness of options.

We focus on quarterly contract expirations, with ED1 denoting the current-quarter contract, ED2 the contract for the following quarter, and so forth. For each trading date and expiration we first select out-of-the-money puts and calls with prices above the minimum tick size, and calculate the risk-free interest rate and $P_{t, T}$ based on the zero-coupon yield curve of Gürkaynak et al. (2007). ${ }^{31}$ To accurately approximate the integral in (A.3) we obtain a smooth call-price function $\hat{c}(K)$ by translating observed option prices into Black (1976) implied volatilities (IVs), linearly interpolating the IVs, and translating the fitted IVs back into call prices. For strikes outside the range of observed option prices we use the IV at the bounds of the range. Note that we do not assume the validity of the Black model but just use it to fit a function in strike/IV space which is more reliable than fitting in strike/price space (Jiang and Tian, 2005). With the smooth function in hand we then calculate the integral in A.3 using the trapezoidal rule over a grid of 120 strikes in an interval of \pm 3 around $F_{t, T}$.

The maturity of Eurodollar contracts follows a sea-saw pattern due to the fixed expiration dates. We use linear interpolation to construct constant maturities. Specifically, we linearly interpolate the conditional variances to obtain $\operatorname{Var}_{t}\left(L_{t+h}\right)$ for contant $h$. For most of our analysis, we will focus on the one-year horizon, which is both sufficiently long to measure policy uncertainty beyond just the next one or two FOMC meetings, and is available for our whole sample period.

\section{A.2 LIBOR-OIS spread}

First we note that derivates based on the Fed's policy rate, the federal funds rate, are available and could in principle be used for our purpose, eliminating concerns about spreads. But there are a number of practical reasons against using federal funds futures and options for our purpose, mainly that the liquidity and data availability of federal funds options is too limited. For these reasons most empirical work using money market options for analysis of monetary policy has focused on Eurodollar options (Neely, 2005; Swanson, 2006; De Pooter et al., 2021; Bundick et al., 2017).

\footnotetext{
${ }^{30}$ Our result resembles the swaption-based conditional variance for swap rates in Trolle and Schwartz (2014).

${ }^{31}$ Discounting with term LIBOR or OIS rates - the industry standard before and after the financial crisis, respectively - makes no practical difference for our results, but data on these rates are not easily available going back to the 1990s.
} 
Since our ultimate interest is in the uncertainty about the future fed funds rate, we have to contend with the fact that LIBOR trades at a spread over the funds rate, due to the inherent risk of a three-month interbank loan vis-a-vis an overnight loan, and that this spread varies over time. The difference between LIBOR and the funds rate is best measured by the LIBOROIS spread, which is calculated from rates with the same maturity and a widely used indicator of financial stress. Specifically, the LIBOR-OIS spread is the difference between three-month LIBOR and the three-month OIS rate, which is closely tied to the fed funds rate. The reason is that the fed funds rate measures the rate on overnight loans, hence it is not comparable to three-month LIBOR. Rates on "Overnight Indexed Swaps" (OIS) with a three-month tenor reflect the market's (risk-neutral) expectation for the fed funds rate over this period.

Table A.1: Summary statistics for LIBOR-OIS and one-year $S R U$ (in basis points)

\begin{tabular}{lcccc}
\hline & \multicolumn{2}{c}{ LIBOR-OIS } & & $S R U$ \\
\cline { 2 - 3 } Subsample & Mean & SD & & Mean \\
\hline Jan-2002 to Jun-2007 & 11 & 4 & & 102 \\
Jul-2007 to Jun-2009 & 89 & 59 & & 82 \\
Jul-2009 to Oct-2019 & 20 & 9 & 85 \\
\hline
\end{tabular}

Sample period: January 2002 to October 2019.

Figure A.1 plots three-month LIBOR and OIS rates in the top panel, and the spread between these rates in the bottom panel. The data for these series comes from Bloomberg, and due to limited availability of historical data for OIS rates we start this sample in January 2002. The shaded area corresponds to the period from July 2007 to June 2009, the episode of elevated financial stress and an abnormally large LIBOR-OIS spread which for the purpose of this paper we consider to be the financial crisis period. Table A.1 reports summary statistics for the LIBOR-OIS spread for the period before, during and after the financial crisis. ${ }^{32}$ Before the 2008 financial crisis, LIBOR was closely tied to the funds rate and other short rates, and LIBOR-OIS was low and stable. Over the period from January 2002 to June 2007 its standard deviation was 4 basis points (bps), while $S R U$ averaged about one percent, meaning that essentially all of the measured uncertainty pertains to the funds rate. During the financial crisis LIBOR-OIS spiked up as worries about the health of the banking system translated into dramatically increased interbank borrowing rates, and $S R U$ was thus less useful as a measure of uncertainty about the fed funds rate. By mid 2009, however, LIBOR-OIS returned to relatively low and stable levels, with only occasional and much less pronounced spikes. From July 2009 to the end of our sample, the variability of the spread was somewhat higher than in the pre-crisis period, but its standard deviation (9 bps) remained an order of magnitude smaller than the average level of market-based uncertainty (95 bps).

\footnotetext{
${ }^{32}$ The standard deviation of one-year changes in the LIBOR-OIS spread, arguably the statistic that is most closely comparable to our conditional one-year-ahead standard deviation of future LIBOR, was generally similar to the standard deviation of the level of the LIBOR-OIS spread.
} 
Figure A.1: Three-month LIBOR and OIS rates
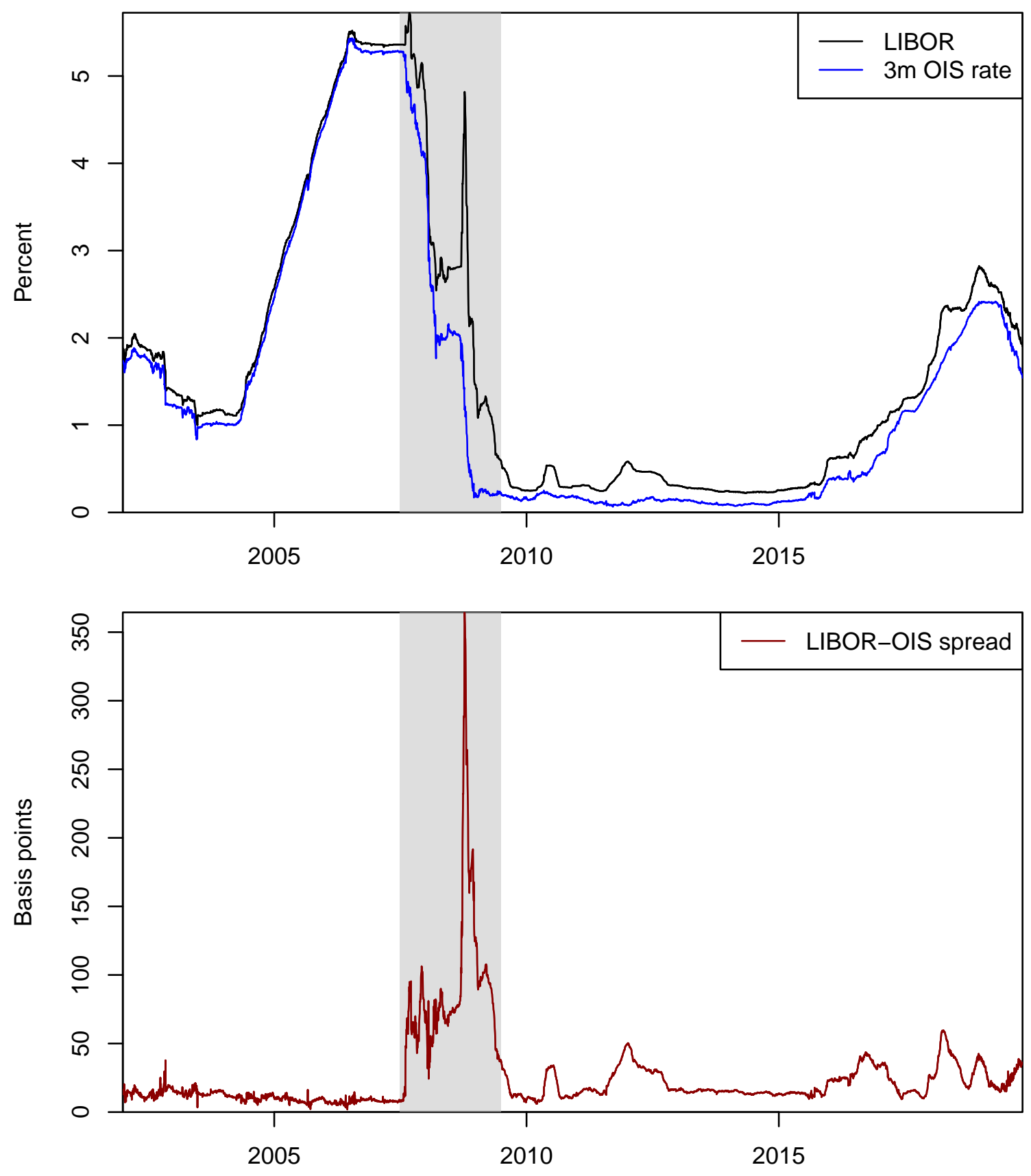

Shaded area: July 2007 to June 2009. Sample period: January 2002 to October 2019. 


\section{A.3 Comparison of uncertainty measures}

We compare our model-free measure of short-rate uncertainty, SRU, with the following alternative market-based measures of short-term interest uncertainty:

- Basis point volatility (BP vol) is the product of Black IV with the futures price. It is based on the assumption of log-normal prices and uses only ATM option prices in the IV calculation. As for SRU, we linearly interpolate this measure to a constant oneyear horizon as well (by interpolating variances). BP vol is also known as "normalized" volatility and empirically almost identical to "normal volatility" which is based on the Bachelier model, that is, on the assumption of a normally distributed price. Because these two measures are almost identical, we only report results for BP vol.

- Bundick et al. (2017) calculate a model-free IV by means of the well-known VIX formula, applied to Eurodollar futures prices. This yields the IV for futures returns, which however is close to the IV for changes in LIBOR, since percent changes and absolute changes are similar for Eurodollar futures prices (which tend to be close to 100). Similarly to our approach, the Bundick measure is also model-free, uses a range of prices across strikes, and, since it uses the VIX, is based on variance swap theory. For our comparison, we use their measure for the four-quarters-ahead Eurodollar contract.

- Swanson (2006) and Swanson and Williams (2014) also calculate a model-free uncertainty measure from Eurodollar option prices, but using a very different approach from ours. They approximate the entire risk-neutral distribution with a flexible non-parametric function, and then measure uncertainty as the interquintile range, i.e., the difference between the 80th and the 20th percentile of this distribution. We use their measure for the four-quarters-ahead Eurodollar contract.

In addition, our comparison in Section 2 also includes common market-based measures of uncertainty about medium- and long-term rates (e.g., 1y/10y swap rates and long-term Treasury yields).

Figure A.2 visually compares our SRU measure with the Bundick and Swanson measures, over the period from 1994 to 2008 where all three measures are available to us. We do not include BP vol in the figure because of its close similarity with SRU (while the levels are similar, daily changes show notable differences, as reported in Table 1). The Bundick measure is quite close to ours, but shows a seesaw pattern due to the changing horizon of the fourquarters-ahead Eurodollar contract. The Swanson measure also has such a seesaw pattern since it also uses a fixed contract, but in addition it is also much more volatile, likely because of the difficulty to approximate the tails of the risk-neutral distribution from the option prices. Measures like ours and the VIX have the benefit that they put weights on option prices that decline with the distance of the strike price from the futures price, and as a result these measures are less affected by measurement error in the tails. 
Figure A.2: Alternative option-based uncertainty measures for future 3-month LIBOR

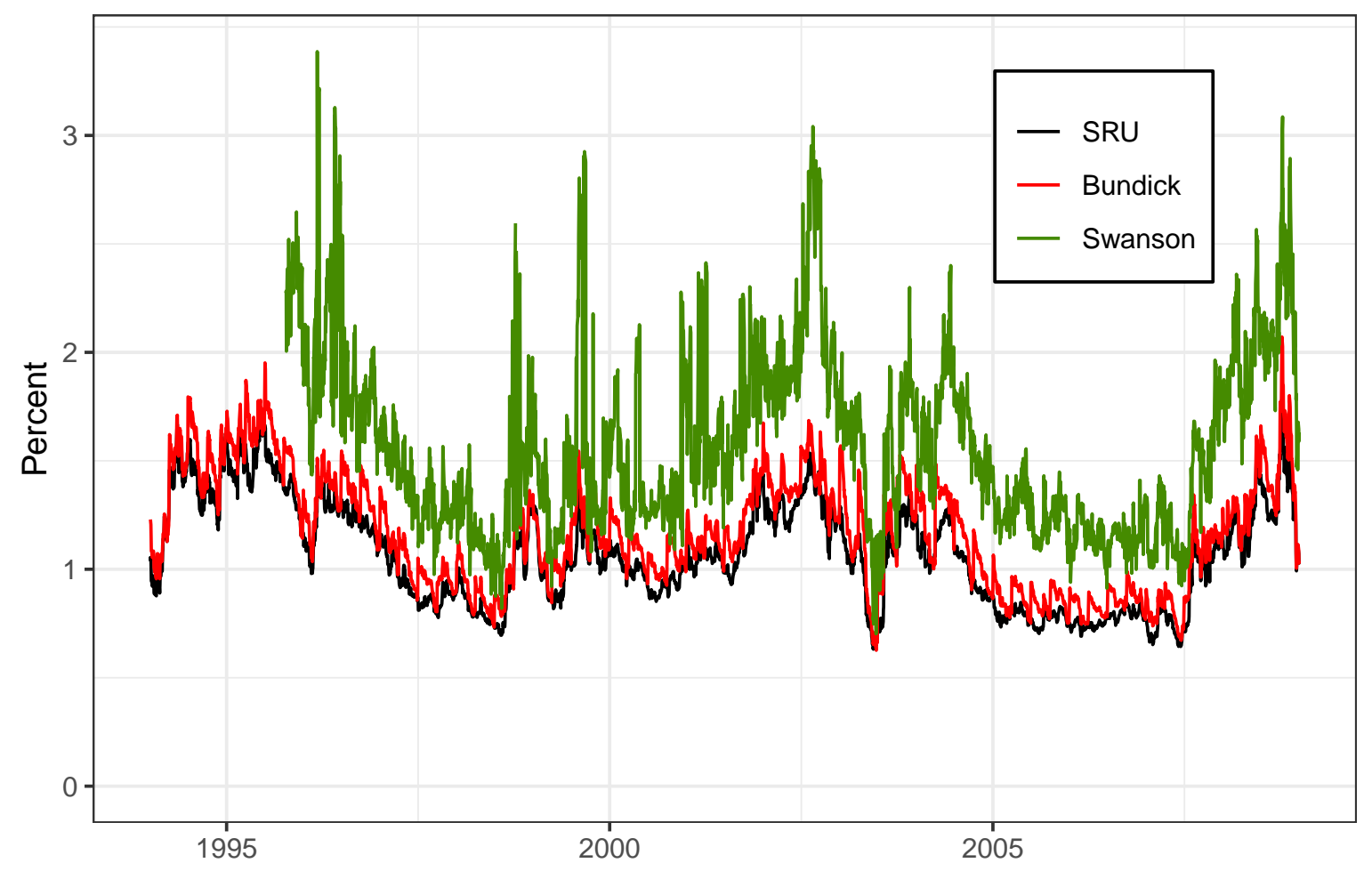

Three daily option-based uncertainty measures for future 3-month LIBOR. SRU: the risk-neutral standard deviation ay a one-year horizon. Bundick: the model-free IV measure for Eurodollar options from Bundick et al. (2017), approximately measuring uncertainty at a four-quarter horizon. Swanson: uncertainty measure of Swanson and Williams (2014) for a four-quarter horizon. Sample period: January 3, 1994, to December 31, 2008.

\section{B Monetary policy vs. macroeconomic uncertainty}

Uncertainty about future short-term interest rates reflects uncertainty about both the macroeconomic outlook and the conduct of monetary policy. Here we present some reduced-form analysis of the relationship between macro uncertainty and our short-rate uncertainty measure, as well as a discussion, based on a simple structural model, of the difficulties of obtaining a meaningful decomposition into these two fundamental sources of uncertainty.

A wide variety of measures has been used in the literature to study macroeconomic uncertainty; for an excellent survey see Cascaldi-Garcia et al. (2020). One particularly influential approach was proposed by Jurado et al. (2015) (JLN), who calculate an econometric measure of macro uncertainty based on the volatility of forecast errors for a wide variety of economic time series. An important advantage of this method is that - in contrast to other widely used uncertainty measures based on volatility or text analysis - it removes predictable variation in the data, and is thus consistent with a definition of uncertainty as the extent to which the future is unpredictable. Recently, a real-time version of this uncertainty measure was proposed by Rogers and Xu (2019), who observe that ex-post and real-time estimates of uncertainty 
using this method can differ quite a bit.

Table B.1 shows regressions of monthly averages of $S R U$ on these macro uncertainty proxies. Over the full sample period from January 1990 to June 2020, the JLN measure is essentially uncorrelated with $S R U$. The Rogers-Xu measure however, which is only available from September 1999 to October 2018, is significantly positively related to $S R U$, with an $R^{2}$ of 0.36. For comparability, we also estimate the regression for the JLN measure over a sample period starting in 1999, which yields a significantly positive relationship and an $R^{2}$ of 0.31 .

Table B.1: Regressions of $S R U$ on macro uncertainty measures

\begin{tabular}{lcccc}
\hline & JLN & JLN & Rogers-Xu & SPF PGDP \\
\hline Intercept & -0.35 & -2.35 & -0.55 & 0.47 \\
Slope & {$[0.20]$} & {$[1.77]$} & {$[1.37]$} & {$[2.78]$} \\
& 1.40 & 3.46 & 14.07 & 0.64 \\
\hline$R^{2}$ & {$[0.76]$} & {$[2.41]$} & {$[3.98]$} & {$[2.94]$} \\
Observations & 0.04 & 0.31 & 0.36 & 0.16 \\
Sample & 366 & 258 & 230 & 123 \\
& Monthly & Monthly & Monthly & Quarterly \\
& 1990:M1-2020:M6 & 1999:M1-2020:M6 & 1999:M9-2018:10 & 1990:Q1-2020:Q1 \\
\hline
\end{tabular}

Regressions of $S R U$ on different measures of macroeconomic uncertainty: the 12-month-ahead macro uncertainty measure of Jurado et al. (2015)(JLN), the corresponding real-time uncertainty estimate from Rogers and $\mathrm{Xu}$ (2019), and the dispersion in the four-quarter-ahead forecasts for the GDP price index in the Survey of Professional Forecasters (SPF). $t$-statistics in squared brackets are based on Newey-West standard errors with automatic lag selection.

We also consider wide variety of survey-based uncertainty proxies, using forecast dispersion in the quarterly Survey of Professional Forecasters for various macro variables and forecast horizons. The only measure that we found to have a significantly positive relationship with (quarterly averages of) $S R U$ is the dispersion about the GDP price index. ${ }^{33}$ This measure has an $R^{2}$ of 0.16 .

These results suggest that some modest amount of the low-frequency variation in $S R U$ could be driven by changes in macroeconomic uncertainty. But because the correlations are generally small, we have found that the residual short-rate uncertainty from these regressions generally still tends to exhibits the cyclical and trend behavior that is evident in Figure 1 of the paper. In any event, our main analysis generally focuses on uncertainty changes around FOMC announcements and not on these low-frequency patterns.

It is worth noting, however, that these reduced-form estimates may well overstate the importance of macroeconomic uncertainty for variation in short-rate uncertainty, for at least two reasons. First, the most popular macro uncertainty proxies, such as the one by JLN, are based on a wide range of macro time series that also include financial variables including

\footnotetext{
${ }^{33}$ All other measures we considered were not significantly correlated with $S R U$, with the only exception being the dispersion about the near-term forecasts for the level of nominal GDP, which were significantly negatively correlated with $S R U$.
} 
interest rates. Because of this overlap, the correlation of "pure" macro uncertainty (i.e., uncertainty only about non-financial macroeconomic variables) is likely smaller than what we estimate. Second, there is also a causation running from monetary policy uncertainty to macroeconomic uncertainty, because uncertainty around the economic outlook is in turn affected by the actions and reactions of monetary policy. In other words, how unpredictable the future course of the macroeconomy is depends also on how unpredictable the central bank is. This is another reason why the strength of the statistical relationship between proxies for macro and short-rate uncertainty documented in Table B.1 likely overstates the true causal importance of macroeconomic uncertainty for $S R U$.

We can make these issues more concrete in the context of a simple structural model, the canonical three-equation New Keynesian model. The Phillips curve, IS curve and a monetary policy rule are:

$$
\begin{aligned}
\pi_{t} & =\beta E_{t} \pi_{t+1}+\kappa y_{t}+u_{t} \\
y_{t} & =E_{t} y_{t+1}+\gamma\left(i_{t}-E_{t} \pi_{t+1}\right)+g_{t} \\
i_{t} & =\alpha \pi_{t}+\beta y_{t}+\varepsilon_{t},
\end{aligned}
$$

where $\pi_{t}$ is inflation, $y_{t}$ is the output gap, $i_{t}$ is the short-term nominal interest rate, $u_{t}$ is a supply or cost-push shock, $g_{t}$ is a demand shock, and $\varepsilon_{t}$ is a monetary policy shock. In this simple model, monetary policy uncertainty comes from $\varepsilon_{t}$ while macro uncertainty comes from $u_{t}$ and $g_{t}$. For simplicity, we are ignoring other potential sources of monetary policy uncertainty which could come from changes in the policy rule. The conditional variance of the short rate is

$$
\operatorname{Var}_{t}\left[i_{t+h}\right]=\alpha^{2} \operatorname{Var}_{t}\left[\pi_{t+h}\right]+\beta^{2} \operatorname{Var}_{t}\left[y_{t+h}\right]+\operatorname{Var}_{t}\left[\varepsilon_{t+h}\right]+\text { covariance terms }
$$

Clearly, short-rate uncertainty is driven by monetary policy uncertainty, but also by uncertainty about inflation and the output gap. This is the main reason why the time series of $S R U$ cannot be interpreted as being driven only by monetary policy uncertainty. A more subtle issue is that macroeconomic variables are endogenous to monetary policy, and thus $\operatorname{Var}_{t}\left[\pi_{t+h}\right]$ and $\operatorname{Var}_{t}\left[y_{t+h}\right]$ are also affected by monetary policy uncertainty. ${ }^{34}$ The consequence is that a decomposition of $S R U$ into monetary policy and macro uncertainty could not be accomplished with a reduced-form analysis that uses empirical proxies for $\operatorname{Var}_{t}\left[\pi_{t+h}\right]$ and $\operatorname{Var}_{t}\left[y_{t+h}\right]$ to directly estimate equation (B.4). Such a decomposition, similar in principle to the regressions in Table B.1, would tend to overstate to important of macroeconomic uncertainty for shortrate uncertainty. An accurate decomposition using different uncertainty proxies would require estimation of a structural model. We view this as a promising avenue for future research.

An alternative approach for measuring policy uncertainty that has been used successfully in the literature is to estimate a policy rule such as equation (B.3) as a stochastic volatility model (Creal and Wu, 2017; Fernández-Villaverde et al., 2015). The estimated volatility series of the residual can then serve as a proxy for monetary policy uncertainty. This is a fundamentally

\footnotetext{
${ }^{34}$ To see this more formally, gather the three variables into $Z_{t} \equiv\left(\pi_{t}, y_{t}, i_{t}\right)$ and the three shocks into $E_{t} \equiv\left(u_{t}, g_{t}, \varepsilon_{t}\right)$, the solution to this model can be written as $Z_{t}=\Psi Z_{t-1}+\Gamma E_{t}$. Thus $\pi_{t}$ and $y_{t}$ will explicitly depend on $\varepsilon_{t}$ which will make $\operatorname{Var}_{t}\left[\pi_{t+h}\right]$ and $\operatorname{Var}_{t}\left[y_{t+h}\right]$ depend on $\operatorname{Var}_{t}\left[\varepsilon_{t+h}\right]$
} 
different route than using market-based measures (or other observable proxies) of uncertainty about the policy instrument, as we do in our paper.

A separate issue is that both approachs - either using uncertainty proxies and an estimated structural model, or estimating equation (B.3) using stochastic volatility methods - require data that is generally available only at monthly or lower frequencies. Therefore, they are of little use for the purpose of our paper, which is to investigate high-frequency changes in monetary policy uncertainty around FOMC announcements and their role for the transmission of policy actions to financial markets.

\section{A simple model of FOMC jumps}

We specify a simple model of short-term interest rates that treats FOMC announcements as short-rate jumps occuring at deterministic times, as in Piazzesi (2001). Our model is essentially the classic Bachelier model, in which asset price changes are normally distributed, augmented with deterministic jumps. We specify the model for the LIBOR rate $L_{t}$ which follows the stochastic differential equation

$$
d L_{t}=\sigma d W_{t}+d J_{t}, \quad J_{t}=\sum_{j=1}^{N_{t}} Z_{j}
$$

where $W_{t} \sim N(0, t)$ is a standard Brownian motion and $J_{t}$ is a jump process with deterministic jump times on FOMC days $\tau_{j}$. The jumps $Z_{j}$ are normally distributed with mean zero and variance $\sigma_{j}^{2}$, and $N_{t}$ is the (known) number of jumps up to time $t .{ }^{35}$ The market-based variance of FOMC jumps is $\sigma_{j}^{2}$. The solution to (C.1) is $L_{t}=L_{0}+\sigma W_{t}+\sum_{j=1}^{N_{t}} Z_{j}$, and the conditional variance of the future short rate is

$$
\operatorname{Var}_{t} L_{T}=(T-t) \sigma^{2}+\sum_{j: t<\tau_{j} \leq T} \sigma_{j}^{2}
$$

where the sum is over all jumps occurring after time $t$ up to and including $T$. This expression shows us what our option-based variance measure captures, according to this simple model: the (scaled) diffusion variance plus the sum of all the jump variances for all FOMC meetings until the contract's expiration date.

The model has strong implications for changes around FOMC meetings. If $t$ is the day of FOMC meeting $j$ (so that $t=\tau_{j}$ ) we have

$$
\Delta \operatorname{Var}_{t} L_{T}=\operatorname{Var}_{t} L_{T}-\operatorname{Var}_{t-\delta} L_{T}=-\delta \sigma^{2}-\sigma_{j}^{2}<0,
$$

where $\delta$ is one trading day measured in years (about 1/250). For days without FOMC meetings the change in the variance is just $-\delta \sigma^{2}$. That is, the model predicts that the conditional variance should decline more on FOMC days than on other days. For changes in $S R U_{t, T}$, the

\footnotetext{
${ }^{35}$ All distributions are specified under a market-based/risk-neutral probability measure.
} 
Table C.1: Summary statistics for changes around FOMC announcements across contracts

\begin{tabular}{lcccccc}
\hline \multicolumn{1}{c}{ ED1 } & ED2 & ED3 & ED4 & ED5 & ED6 \\
\hline \multicolumn{2}{l}{ Changes in conditional variance } & & & & \\
Mean & -0.009 & -0.017 & -0.026 & -0.033 & -0.037 & -0.041 \\
$t$-statistic & -8.861 & -9.602 & -8.745 & -8.286 & -7.743 & -8.054 \\
Median & -0.004 & -0.008 & -0.015 & -0.016 & -0.020 & -0.024 \\
Standard deviation & 0.013 & 0.025 & 0.042 & 0.056 & 0.068 & 0.072 \\
\hline Changes in $S R U$ & & & & & & \\
Mean & -0.019 & -0.018 & -0.019 & -0.018 & -0.017 & -0.017 \\
$t$-statistic & -11.791 & -12.434 & -10.916 & -10.126 & -9.130 & -9.003 \\
Median & -0.013 & -0.013 & -0.015 & -0.013 & -0.013 & -0.013 \\
Standard deviation & 0.021 & 0.020 & 0.024 & 0.025 & 0.027 & 0.026 \\
\hline Observations & 177 & 197 & 197 & 197 & 197 & 194 \\
Fraction negative & 0.09 & 0.12 & 0.19 & 0.15 & 0.19 & 0.19 \\
\hline
\end{tabular}

Summary statistics for daily changes around FOMC announcements in variance $\left(\Delta V a r_{t, T} L_{T}\right.$, top panel) and uncertainty $\left(\Delta S R U_{t, T}\right.$, bottom panel). $t$-statistics are calculated using White heteroskedasticity-robust standard errors. Sample: 197 scheduled FOMC meetings between January 1994 and September 2020, excluding the period from July 2007 to June 2009 containing the Global Financial Crisis (some observations are missing for contracts ED1 and ED6 due to option data availability).

square root of the conditional variance, around the day of FOMC meeting $j$ we have

$$
\Delta S R U_{t, T}=S R U_{t, T}-S R U_{t-\delta, T}=\sqrt{(T-t) \sigma^{2}+\sum_{i} \sigma_{i}^{2}}-\sqrt{(T-t+\delta) \sigma^{2}+\sigma_{j}^{2}+\sum_{i} \sigma_{i}^{2}}<0,
$$

where the $\sigma_{i}^{2}$ 's are the variances for the remaining FOMC jumps after date $\tau_{j}$ until $T$. Note that our baseline measure of $S R U$ shown in Figure 1 and 2 is a constant-horizon measure calculated by interpolating multiple contracts while the equation above is for a fixed contract expiration.

\section{C.1 Evidence for FOMC jumps and resolution of uncertainty}

Table C.1 reports evidence for changes around FOMC announcements in the variance and uncertainty for each individual Eurodollar contract ED1 to ED6. The top panel shows summary statistics for changes in the variance, $\Delta V a r_{t} L_{T}$, and the bottom panel for changes in uncertainty, $\Delta S R U_{t, T}$. The means are all negative and strongly significant. The medians are higher because of the fat left tails. The average decline in $S R U$ is between 1.5 and 1.9 bps, in line with the results in Section 3 for the one-year measure.

Through the lens of our simple model, uncertainty decreases every day due to a shortening of the horizon, but it decreases by more around FOMC meetings. Thus, for understanding the importance of FOMC jumps we need to compare days with FOMC meetings to other days. Table C.2 shows results for regressions of changes in variance and $S R U$ on a dummy variable 
Table C.2: FOMC days vs. non-FOMC days across contracts

\begin{tabular}{lcccccc}
\hline \multicolumn{1}{c}{ ED1 } & ED2 & ED3 & ED4 & ED5 & ED6 \\
\hline Changes in conditional variance & & & & & \\
Constant & -0.001 & -0.002 & -0.003 & -0.004 & -0.005 & -0.005 \\
& {$[-11.85]$} & {$[-10.97]$} & {$[-9.54]$} & {$[-8.64]$} & {$[-7.50]$} & {$[-6.15]$} \\
FOMC dummy & -0.007 & -0.015 & -0.023 & -0.028 & -0.032 & -0.037 \\
& {$[-7.40]$} & {$[-8.18]$} & {$[-7.51]$} & {$[-7.09]$} & {$[-6.67]$} & {$[-7.05]$} \\
$R^{2}$ & 0.028 & 0.022 & 0.019 & 0.015 & 0.013 & 0.012 \\
Memo: estimated jump vol. & 0.084 & 0.122 & 0.152 & 0.167 & 0.179 & 0.192 \\
\hline Changes in SRU & & & & & & \\
Constant & -0.003 & -0.003 & -0.003 & -0.003 & -0.002 & -0.002 \\
& {$[-15.88]$} & {$[-13.07]$} & {$[-11.37]$} & {$[-10.47]$} & {$[-9.21]$} & {$[-7.76]$} \\
FOMC dummy & -0.015 & -0.015 & -0.016 & -0.016 & -0.015 & -0.014 \\
& {$[-9.60]$} & {$[-10.37]$} & {$[-9.22]$} & {$[-8.53]$} & {$[-7.74]$} & {$[-7.75]$} \\
$R^{2}$ & 0.038 & 0.025 & 0.022 & 0.019 & 0.016 & 0.014 \\
\hline Observations & 4922 & 6228 & 6230 & 6230 & 6230 & 6176 \\
\hline
\end{tabular}

Regressions of changes in variance $\left(\Delta \operatorname{Var}_{t, T} L_{T}\right.$, top panel) and uncertainty $\left(\Delta S R U_{t, T}\right.$, bottom panel) on a dummy variable for days with FOMC announcements. $t$-statistics in squared brackets are calculated using White heteroskedasticity-robust standard errors. Sample period: January 1994 and September 2020, excluding the period from July 2007 to June 2009 covering the Global Financial Crisis (some observations are missing for contracts ED1, ED2 and ED6 due to option data availability).

for days with FOMC announcements. The estimated intercepts show that the average change in uncertainty on non-FOMC days is negative, in line with the prediction of the model. (This contrasts with the results in Table 2 which do not show an average decline for non-FOMC days, since those results are based on our one-year uncertainty measure.) The dummy coefficients implz that the decline around FOMC meetings is much larger than on other days, and that the difference has very high statistical significance, consistent with Table 2. For changes in conditional variance, in the top panel, these coefficients estimate the average of the negative jump variances, $-\sigma_{j}^{2}$, and the table also reports the implied average jump volatility, which range from 8 to 19 bps. These numbers are substantially larger than the average decline in $S R U$ due to FOMC announcements ("resolution of uncertainty") which is around 1.5 bps. The reason is that these measure something quite different, namely the changes in the market-based standard deviation for the future short rate, as opposed to the jump volatility of a typical FOMC meeting. The jump model is helpful in interpreting these quantities. Overall, the sizeable positive jump variances and systematic decline in uncertainty around FOMC days are consistent with the presence of substantial FOMC jumps. ${ }^{36}$

\footnotetext{
${ }^{36}$ This analysis gives us "ex post estimates" of the FOMC jump variance, a term originating from Dubinsky et al. (2018) who consider deterministic jumps in stock prices around earnings announcements. They also suggest an ex ante estimate of jump variances, but this estimate is difficult to implement in our setting, since it requires that two successive futures contracts span the same FOMC meetings and we focus on contracts with quarterly expirations; contracts with monthly expirations are distinctly less liquid and have less historical
} 
According to our model non-FOMC days only experience diffusion variance $\delta \sigma^{2}$, but more generally these days also exhibit jumps in interest rates, mainly due to macro announcements such as the release of the employment report by the Bureau of Labor Statistics (Johannes, 2004; Kim and Wright, 2014). The estimates in Table C.2 indicate that FOMC jumps lead to much larger changes in market-based variance than on other days, even though many of these other days also include some other types of jumps.

\section{C.2 Extending the model: beliefs about jump variances}

Taken literally, the model implies that (i) market-based variance should always decline around FOMC meetings, (ii) variation in the declines over time are only due to differences in the jump variances $\sigma_{j}^{2}$, and (iii) all contracts should exhibit identical declines. However, (i) uncertainty sometimes increases around FOMC announcements (for about 10-20\% of the announcements), (ii) the variability of changes in conditional variance appears larger than can plausibly be explained by differences in jump variances $\sigma_{j}^{2}$, and (iii) different Eurodollar contracts do not deliver identical jump variance estimates. Regarding the last point: The means in Table C.1 differ notably across contracts, and the first principal component explains only $87 \%$ of the variation of daily changes in conditional variance. The empirical deviations from the model's implications seem larger than what could be attributed to market noise or measurement error.

A simple extension of the model can reconcile these observations: While the jump variances were so far assumed to be fixed and known, a more realistic assumption is that market participants form beliefs about future jump variances, $E_{t} Z_{j}^{2}$, and update these beliefs based on new information. In this case changes in $\operatorname{Var}_{t} L_{T}$ not only reflect the mechanical "droppingout" of the most recent FOMC jump, but also changes to the jump variance beliefs due to the current policy announcement. With this generalization, we have

$$
\Delta \operatorname{Var}_{t} L_{T}=-\delta \sigma^{2}-\sigma_{j}^{2}+\sum_{i: t<\tau_{i} \leq T}\left(E_{t}-E_{t-\delta}\right) Z_{i}^{2} .
$$

(Here, $\sigma_{j}^{2}$ is the most recent belief of the jump variance, i.e., $\sigma_{j}^{2}=E_{t-\delta} Z_{j}$. Note that $t=\tau_{j}$.) If future jump variance beliefs increase sufficiently as a result of an FOMC announcement, market-based uncertainty can increase. More generally, changes in beliefs contribute additional variation to market-based variance and $S R U$, both over time and across contracts. The FOMC dummy regressions still yield valid estimates of (the negative) average jump variances to the extent that the belief updates average to about zero. While the presence of jumps provides an explanation for the tendency of $S R U$ to decline around FOMC announcements, changes in the beliefs about jump variances can explain why there is substantial variation in uncertainty changes around FOMC announcements, including a fair number of days with increases in uncertainty. This slight generalization of the model is therefore a more plausible description of FOMC jumps and interest rate uncertainty. ${ }^{37}$

\footnotetext{
data.

${ }^{37}$ Another possible but more complicated extension would be to allow for stochastic volatility of the diffusion term, as in Dubinsky et al. (2018).
} 


\section{C.3 Jump risk premia}

A question that naturally arises from our analysis of FOMC jumps is whether there are jump risk premia. If market-based estimates of jump variances differ from actual, real-world variance of FOMC jumps, this would suggest that investors require compensation for bearing jump risk that drives a wedge between the two.

It turns out that market-based volatility around FOMC announcements is indeed substantially larger than historical volatility, suggesting the likely presence of jump risk premia. The negative of the mean change in conditional variance around FOMC meetings reported in Table C. 1 corresponds to volatilities between 9 and 20 bps. Here we want to include not only the jumps but also the diffusion part, which is why we use the mean changes in marketbased variances in Table C.1 (the average of $-\delta \sigma^{2}-\sigma_{j}^{2}$ ), instead of the dummy coefficients in Table C.2 (the average of $-\sigma_{j}^{2}$ ). By contrast, the standard deviations of daily changes in three-month LIBOR around FOMC announcements is only $1.5 \mathrm{bps}$; including the crisis period and all unscheduled FOMC announcements increases this volatility but only to 1.9 bps. The fact that historical volatilities are so much smaller than market-based volatilities is quite striking. Given the pronounced interest rate risk investors are exposed to around FOMC announcements, it seems plausible that jump risk premia play a role in accounting for this difference.

In a similar comparison of option-based and historical jump volatilities for stock returns around earning announcements, Dubinsky et al. (2018) find that return volatility under the market-based measure is $8.2 \%$ and thus slightly higher than the return volatility under the phyiscal measure of $7.4 \%$. Our relative differences in volatility are an order of magnitude larger, suggesting that jump risk premia are quantitatively much more important for interest rate movements around FOMC announcements than they are for stock returns around company earnings announcements.

To obtain sharper evidence on the presence of jump risk premia we ask whether investors can profitably exploit the pattern we have documented using an option-trading strategy. If the market-based jump volatilities are truly larger than historical jump volatilities, then writing straddles with Eurodollar options should be a profitable strategy, similar to the case of earnings announcements in Dubinsky et al. (2018). We calculate returns on straddle positions around scheduled FOMC announcements, that is, on a position including both a call and a put contract with the same, at-the-money strike price. ${ }^{38}$ Table C.3 reports summary statistics for both relative returns and absolute returns for this option strategy. Average returns are significantly negative, with mean relative returns ranging from about -2 to -9 percent across contracts (with larger negative returns at short horizons, due to smaller straddle prices), and mean absolute returns around -1.4 bps. There is some skewness, with median returns slightly above mean returns, and high excess kurtosis as often observed in daily financial market returns. The key statistic is the Sharpe ratio, which we calculate for a short straddle strategy and annualize in the same way as Lucca and Moench (2015) using $\sqrt{8}$ times the per-meeting Sharpe ratio, since there are typically eight scheduled FOMC meetings per year. The Sharpe

\footnotetext{
${ }^{38}$ Such a position has a small but non-zero exposure to movements in the underlying price. It is possible but in our case not necessary to construct delta-neutral straddle portfolios, meaning that they are unaffected by marginal movements in the underlying price, see Ederington and Lee (1996).
} 
Table C.3: Returns on Eurodollar option straddles around FOMC announcements

\begin{tabular}{lcccccc}
\hline & ED1 & ED2 & ED3 & ED4 & ED5 & ED6 \\
\hline Relative returns & & & & & \\
Mean & -9.1 & -4.5 & -3.0 & -2.3 & -2.1 & -1.6 \\
Median & -8.3 & -4.2 & -2.8 & -2.2 & -1.7 & -1.4 \\
SD & 11.9 & 6.1 & 4.5 & 4.1 & 3.7 & 3.3 \\
Skewness & -0.3 & -0.6 & 0.1 & -0.5 & -3.2 & -0.9 \\
Kurtosis & 5.5 & 7.6 & 7.4 & 19.4 & 23.5 & 14.7 \\
$t$-statistic & -10.8 & -10.5 & -9.2 & -7.8 & -8 & -6.8 \\
Sharpe ratio & 2.2 & 2.1 & 1.8 & 1.6 & 1.6 & 1.4 \\
\hline Absolute returns & & & & & & \\
Mean & -1.3 & -1.3 & -1.4 & -1.4 & -1.4 & -1.3 \\
Median & -1 & -1 & -1 & -1 & -1 & -1 \\
SD & 1.8 & 1.9 & 2.2 & 2.2 & 2.4 & 2.4 \\
Skewness & -0.8 & -0.7 & -0.6 & -1.1 & -1.4 & -0.8 \\
Kurtosis & 6.3 & 6.7 & 5.6 & 6.7 & 8 & 6.7 \\
$t$-statistic & -10.2 & -10 & -8.6 & -8.7 & -8.5 & -7.9 \\
Sharpe ratio & 2.1 & 2 & 1.7 & 1.7 & 1.7 & 1.6 \\
\hline Observations & 197 & 197 & 197 & 197 & 197 & 194 \\
\hline
\end{tabular}

Summary statistics for returns on option straddles with at-the-money contracts around scheduled FOMC meetings. The top panel reports relative returns in percent, and the bottom panel reports absolute returns in basis points. The holding period is one day, from the close on the day before the meeting to the close on the day of the meeting. The Sharpe ratios are calculated for short straddles and are annualized by multiplying by $\sqrt{8}$ because there are about eight FOMC meetings per year, as in Lucca and Moench (2015). ED1 is the Eurodollar contract expiring at the end of the current quarter, ED2 expires at the end of the next quarter, and so forth. Sample period: Jan-1994 to Sep-2020, excluding the period from Jul-2007 to Jun-2009 covering the Global Financial Crisis.

ratios are large, ranging from about 1.4 at longer contracts to 2.2 at shorter contracts, suggesting high risk-adjusted average returns to short straddle positions around FOMC meetings. ${ }^{39}$ By comparison, the pre-FOMC announcement returns in Lucca and Moench (2015) have annualized Sharpe ratios around 1.1. These results suggest that investors might potentially be able to profitably exploit the systematic declines in interest-rate uncertainty round FOMC announcements, consistent with the presence of FOMC jump risk premia.

Like Dubinsky et al. (2018), we do not systematically account for transaction costs in our calculation, as our data includes daily settlement prices but not bid/ask prices. At-the-money option contracts for near-term expirations - those where short straddles are most profitable tend to be very liquid. While bid-ask spreads are typically on the order of 0.5 to 1.0 basis points and would seem to eat up most of the returns, trading costs in liquid option markets tend to be much lower than quoted bid-ask spreads (Muravyev and Pearson, 2020). We leave

\footnotetext{
${ }^{39}$ In additional, unreported results we have found very similar results for separate pre- and post-crisis samples (with slightly larger Sharpe ratios before than after the crisis).
} 
Table D.1: Change in monetary policy uncertainty and pre-FOMC drift

\begin{tabular}{lcc}
\hline & Feb-1994 to Dec-2017 & Feb-1994 to Mar-2011 \\
\cline { 2 - 3 } & excl. crisis & incl. crisis \\
\hline \multirow{3}{*}{ pre-FOMC drift } & -0.004 & -0.006 \\
& {$[-1.61]$} & {$[-3.66]$} \\
Constant & -0.016 & -0.020 \\
& {$[-7.37]$} & {$[-7.93]$} \\
$R^{2}$ & 0.010 & 0.058 \\
Observations & 176 & 138 \\
\hline
\end{tabular}

Regression of change in monetary policy uncertainty on the pre-FOMC drift in the stock market on scheduled FOMC days. The pre-FOMC drift is measured as the cumulative change in the S\&P 500 futures index in a 24 hour window leading up to the announcement time (typically 2:15pm). The first column covers a sample from January 1994 to December 2017, excluding the period from July 2007 to June 2009 covering the global financial crisis. The second column shows results for the sample of Lucca and Moench (2015), from January 1994 to March 2011. In brackets are $t$-statistics calculated using White heteroskedasticity-robust standard errors.

a more detailed analysis of the profitability of our proposed trading strategy to practitioners and future research.

\section{Additional empirical results for Section 3}

\section{D.1 Resolution of uncertainty and FOMC pre-announcement drift}

The following evidence speaks to the question of whether short-rate uncertainty gets resolved before or after the actual FOMC announcement. We show that MPU is only weakly correlated with the pre-FOMC drift in the stock market documented by Lucca and Moench (2015). Hu et al. (2019) document a tight link between drop in the VIX and the pre-FOMC stock market drift, in line with the finding that the VIX falls before the announcement. By contrast, there is only a very weak link between $M P U$ and the pre-FOMC drift, as shown in Table D.1. For the Lucca and Moench (2015) sample, the coefficient is statistically significant, but for the period from 1994 to 2017 the coefficient is insignificant. In both sample periods, the $R^{2}$ is very low, and for the 1994-2017 period it is only 0.01. In addition to the weak correlation, the size of the effect is also small: For the 1994-2017 period a pre-FOMC drift of around 50bps is associated with a drop in $M P U$ of only 0.3 bps. Recall that the average fall in $M P U$ is 1.6 bps and the standard deviation is 2.5 bps. We have also rerun our main results orthogonalizing $M P U$ measure with respect to the pre-FOMC stock market drift and found essentially identical results. Thus overall, most of the variation in $M P U$ appears to be unrelated to the preannouncement drift in the stock market, consistent with the view that policy uncertainty changes after the release of the statement. 
Figure D.1: Monetary policy surprises and changes in uncertainty

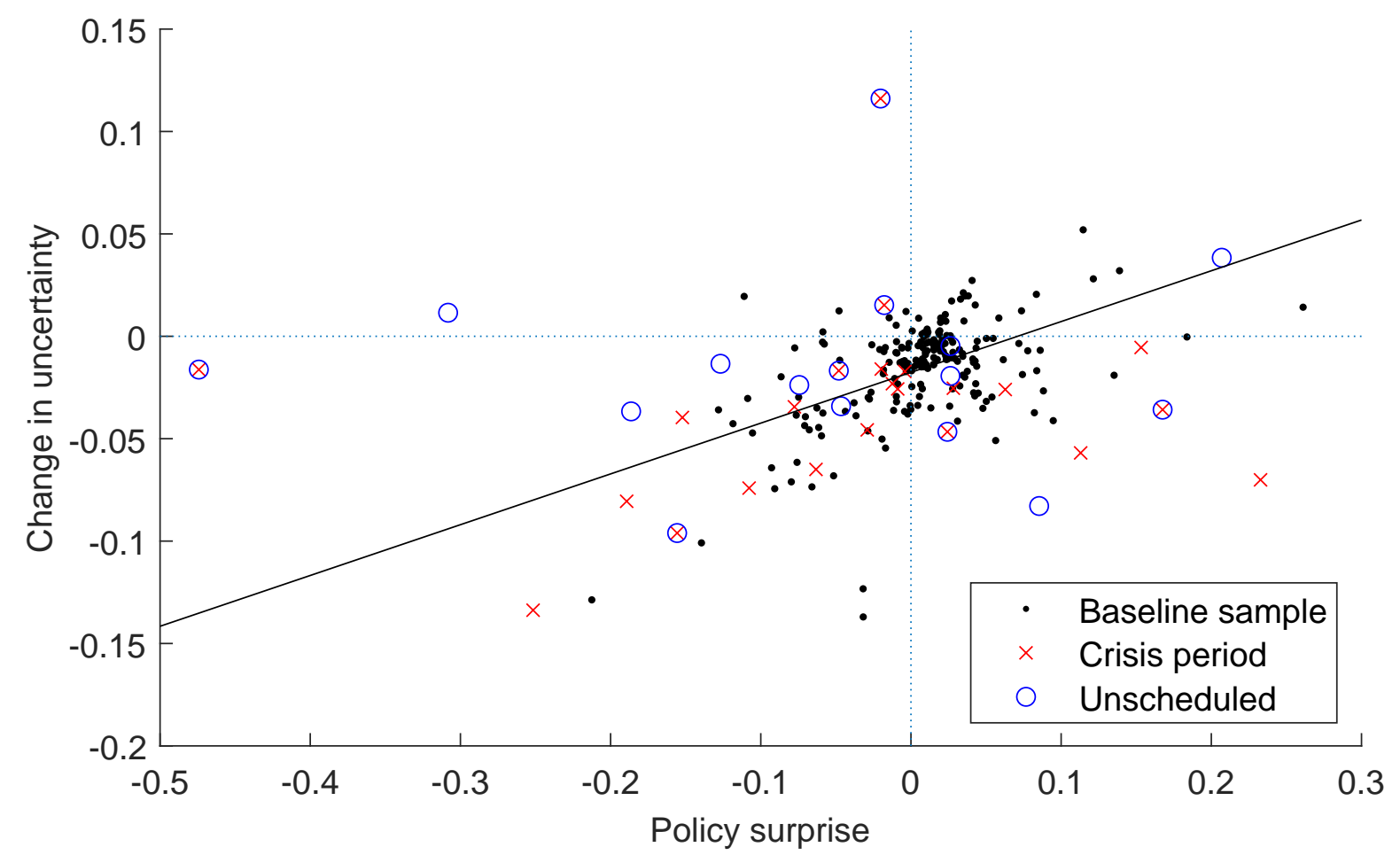

Scatter plot of the daily change in monetary policy uncertainty against the policy surprise on FOMC announcement days. The full sample consists of FOMC announcements from January 1994 to September 2020, the baseline sample excludes unscheduled announcements and also excludes the period from July 2007 to June 2009 containing the Global Financial Crisis. The black line shows the fit from the regression of change in uncertainty on policy surprise for the baseline sample.

\section{D.2 FOMC first moment surprises and policy uncertainty}

The scatter plot in Figure D.1 plots changes in policy uncertainty around FOMC meetings $(M P U)$ against our baseline measure of first moment monetary policy shocks $(M P S)$. The figure shows a clear positive correlation, consistent with the positive correlation between changes in futures rates and uncertainty reported in Section 2. We report the coefficients from regressing $M P U$ on $M P S$ in the first column of Table D.2, and the slope coefficient is very strongly statistically significant.

The literature has also used other event-study measures of FOMC policy surprises. The second column of Table 2 reports estimates of regressions of $M P U$ on the target and path factors of the monetary surprise from Gürkaynak et al. (2005a). Both are significantly positively related to changes in uncertainty, but the association is much stronger for the path factor. The third column of Table D.2 shows results for regressions on the target factor and the delphic and odyssean forward guidance factors of Andrade and Ferroni (2020), which are identified based on their correlation with changes in TIPS breakeven inflation rates. Both forward guidance factors are similarly strongly related to changes in uncertainty.

The positive correlation between $M P S$ and $M P U$ raises the question of whether the average decline in uncertainty around FOMC announcements is simply due to the prevalence 
Table D.2: Monetary policy surprises and uncertainty

\begin{tabular}{lccc}
\hline & $1 / 94$ to $9 / 20$ & $1 / 94$ to $9 / 20$ & $2 / 99$ to $9 / 20$ \\
\hline MPS & 0.197 & & \\
& {$[5.67]$} & & \\
GSS Target & & 0.061 & \\
& & {$[2.11]$} & \\
GSS Path & & 0.224 & \\
& & {$[6.32]$} & \\
AF Target & & & 0.135 \\
& & & {$[3.34]$} \\
AF Delphic & & & 0.146 \\
& & & {$[2.89]$} \\
AF Odyssean & & & 0.151 \\
& & & {$[2.15]$} \\
Constant & -0.016 & -0.016 & -0.014 \\
& {$[-10.03]$} & {$[-10.74]$} & {$[-8.81]$} \\
Observations & 197 & 197 & 157 \\
R-squared & 0.27 & 0.31 & 0.17 \\
\hline
\end{tabular}

Regression of the daily change in monetary policy uncertainty on first moment policy surprises on FOMC announcement days. The first column ("MPS") uses our baseline monetary surprise measure, the second column ("GSS") shows the regression when we use the Gürkaynak et al. (2005a) target and path factors and the third column ("AF") shows the results when we use the Andrade and Ferroni (2020) target, delphic and odyssean factors. The sample consists of scheduled FOMC announcements from January 1994 to September 2020, excluding the period from July 2007 to June 2009 containing the Global Financial Crisis. The sample for the third column starts from February 1999 due to availability of breakeven inflation data. In brackets are t-statistics based on White hetreoskedasticity-robust standard errors.

of dovish policy surprises. Since $M P S$ is the first principal component and therefore has a zero mean by construction, we answer this question by calculating an alternative surprise measure that is not demeaned. This surprise series, which is scaled in the same way as MPS has a sample mean of -0.011 , reflecting the well known fact that the FOMC's policy surprises have been dovish on average. The intercept of a regression of $M P U$ on this surprise measure shows whether the resolution of uncertainty is driven by this pattern. The estimated intercept is -0.014 with a $t$-statistic of -9.6 , which is very similar in terms of magnitude and statistical significance to the sample mean of $M P U$ reported in Table 2 of the paper. This is also true in individual regressions of $M P U$ on rate changes for each futures contract that constitutes the $M P S$ surprise measure - The intercept remains roughly the same size and strongly statistically significant. To conclude, the resolution of uncertainty that we have emphasized is not driven by any mechanical correlation with the first moment surprise. 


\section{D.3 Macroeconomic data releases and uncertainty}

Here we show the impact of macroeconomic data releases on uncertainty, and compare them to FOMC announcements. Table D.3 reports in the first column the results of a regression of daily changes in $S R U$ on dummies for days with six major macro news releases, as well as for scheduled FOMC announcements. Some macro releases also lead to a significant decline in uncertainty, but of smaller magnitude than scheduled FOMC announcements. Among the macro releases, the employment report is associated with the largest decline of $0.8 \mathrm{bps}$, which is strongly significant. However, this is still only about half as large as the decline due to scheduled FOMC meetings of 1.6 bps. No macro release leads to a similarly large resolution of uncertainty as FOMC announcements.

This result is also confirmed by regressions when we include the actual surprise component of the news release interacted with the dummies. The news surprise for macro announcements are the standardized differences between the data release and the consensus expectations. ${ }^{40}$ The second column shows that after controlling for the average change in $S R U$ on news days, the surprise itself does not have big effects on uncertainty. The third column replaces the surprise with the absolute value of the surprise. Larger surprises on FOMC days reduce uncertainty, but there is no systematic relationship between large macroeconomic news surprises and changes in uncertainty. Overall, this evidence shows that FOMC announcements are far more important for short-rate uncertainty than macroeconomic news.

\section{D.4 Fed speeches and policy uncertainty}

Another possibility is that speeches given by Fed policy makers could be creating uncertainty about future short rates. To explore this, in Table D.4 below we show the summary statistics for changes in $S R U$ on days when these speeches were made. The first column considers a speech given by all FOMC members, including governors and presidents. The last three columns focus on the last three Fed chair speech days. As is clear from the table, the mean change in $S R U$ on days with speeches is negligible and statistically insignificant. This rules out the possibility that the uncertainty that is resolved with FOMC announcements is being created on speech days.

\section{D.5 FOMC uncertainty cycle}

Here we investigate in more detail the FOMC uncertainty cycle documented in Figure 3 of the paper. While the evidence for the decline around the FOMC meeting is generally quite sharp and can be explained based on FOMC jumps - see also Appendix C - it is much less clear why uncertainty ramps up over the first two weeks of the intermeeting cycle.

Part of the reason for the FOMC uncertainty cycle documented in the paper is somewhat mechanical: As evident from our simple model, more distant derivative contracts generally contain more uncertainty than shorter contracts, mainly because they cover more FOMC meetings, and also because of general uncertainty (diffusion variance). The one-year $S R U$ measure

\footnotetext{
${ }^{40}$ The consensus expectations are available from the widely used survey by Action Economics, the successor to Money Market Services.
} 
interpolates between two contract expirations, so it contains the uncertainty from the shorter contract plus a share of the additional uncertainty in the longer contract. After an FOMC announcement, uncertainty is lower than usual as there are less than average FOMC meetings within the one-year horizon. Over the intermeeting cycle, the number of announcements priced in the one-year uncertainty, and with it the measured uncertainty, therefore tends to gradually increase.

But the graphical evidence in Figure 3 suggests that the increase in uncertainty appears stronger over the first two weeks after the meeting than over the rest of the cycle. To provide additional evidence on this issue, we consider the dynamics of the change in uncertainty derived from fixed-expiration Eurodollar contracts. We regress these daily changes on dummy variables for the number of days since the last FOMC announcements: whether an announcement happened on the same day, 1-5 trading days before, 6-10 days before, etc., up to 25 days. Table D.5 shows the regression results. The negative constant captures the average decline in uncertainty due to the passage of time, that we should expect from these fixed-expiration measures (see also Table C.2). The negative coefficient on the FOMC dummy reflects the resolution of uncertainty. The coefficients on the weekly dummies estimate how the average change in uncertainty during the weeks after the FOMC announcement differs from the average (the negative intercept). For the first two weeks, the coefficients are significantly positive (with the exception of the shortest contract, ED1), which implies that this is when uncertainty primarily ramps up after the decline around the FOMC announcement. In sum, perceived uncertainty and/or jump risk premia decline below "normal" right after an announcement, possibly due to guidance from the FOMC and a shifting focus of investors, before reverting back within the first two weeks of the intermeeting cycle.

It is also interesting to compare changes in $S R U$ over the FOMC meeting cycle to changes in the VIX. Figure D.2 plots changes in $S R U$ (top panel) and the VIX (bottom panel) over the FOMC cycle, normalized in each case by the full-sample standard deviation of daily changes. The VIX tends to fall on FOMC days, as documented in Fernandez-Perez et al. (2017), Amengual and Xiu (2018) and Gu et al. (2018). However, the decline in short-rate uncertainty is substantially larger. The average one-day decline in the VIX is about 0.4 standard deviations, while $S R U$ falls on average by about 0.8 standard deviations after FOMC announcements. The VIX also does not show a pronounced ramp-up pattern - the VIX has a very modest increase in the days leading up to the FOMC meeting, consistent with the results documented in $\mathrm{Hu}$ et al. (2019). Overall, the uncertainty cycle - the drop around FOMC meetings and the subsequent ramp-up in uncertainty - is much more dramatic for $S R U$ than for the VIX. A plausible explanation for the much larger decline and clear ramp-up pattern in $S R U$ is that it more directly measures the uncertainty about monetary policy, whereas there are many drivers of uncertainty in the stock market, including not only uncertainty about interest rates/discount rates but also about future cash flows/earnings, as well as shifts in investor sentiment. The FOMC directly controls short-term interest rates, whereas its effects on the stock market are much less immediate. This is a possible explanation for why the systematic pattern of $S R U$ over the FOMC meeting cycle is much more pronounced than for the VIX. 
Figure D.2: Changes in short-rate uncertainty and VIX over the FOMC meeting cycle
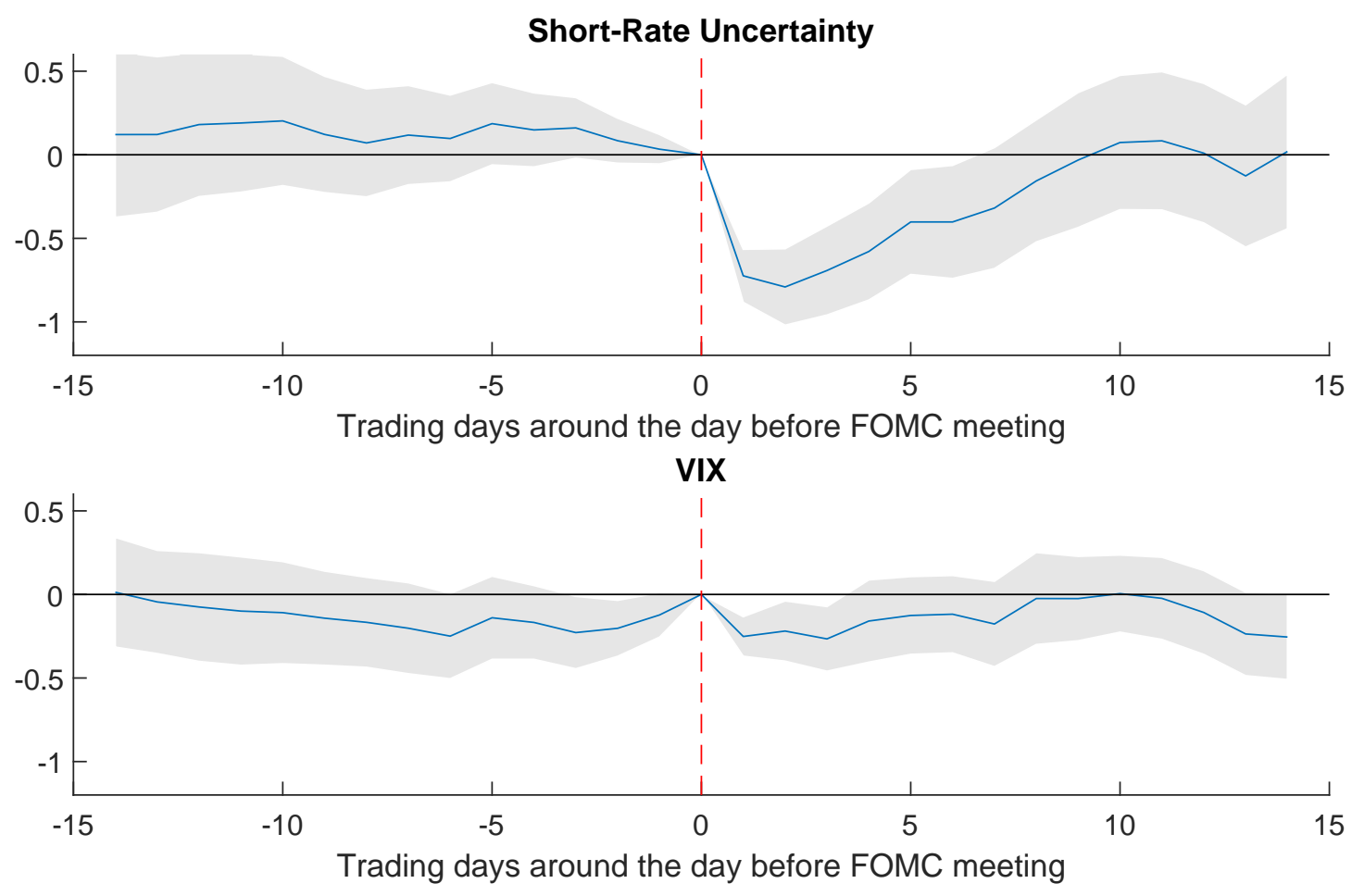

The figure shows the average change in SRU (top panel) and VIX (bottom panel) on trading days around the FOMC announcement, relative to the day before the FOMC announcement day (shown with dashed red line). Both series are normalized to show changes relative to the standard deviation of the daily change of the corresponding series on all days. The shaded gray region shows $95 \%$ confidence intervals constructed using White heteroscedasticity-robust standard errors. The sample includes 197 scheduled FOMC announcements from January 1994 to September 2020.

\section{E Additional results for Section 4}

Tables E.1 and E.2 present additional results for the transmission of monetary policy uncertainty to financial markets. The first table shows the transmission of $M P U$ to Treasury forwards (both nominal and real) following the specification of Hanson and Stein (2015), which uses a two-day window around the FOMC announcement and uses the 2-year rate as the measure of monetary policy surprise. Our results continue to show an important role for monetary policy uncertainty consistent with our baseline specification. The second table shows the transmission of uncertainty to yields, stock and foreign exchange market controlling for broader measures of monetary policy surprise, specifically the target and path factors of Gürkaynak et al. (2005a). Again, the importance of $M P U$ for transmission of monetary policy actions to financial markets remains both economically and statistically significant. 


\section{F Unconventional monetary policy announcements}

The results presented in this section excluded the Global Financial Crisis period. Of course, this was an episode where the FOMC started unconventional policies like quantitative easing (QE) and relied more on other unconventional policies like forward guidance (FG). To understand the role of changes in monetary policy uncertainty for the financial market effects of unconventional monetary policies, we carry out an event study of major FOMC announcements, following a large and growing literature including, among many others, Gagnon et al. (2011), Krishnamurthy and Vissing-Jorgensen (2011) and Bauer and Rudebusch (2014). We choose key events for QE1, QE2, the maturity extension program (MEP), and QE3 among those identified in the existing literature (in particular Bauer and Neely (2014) and Kuttner (2018)) plus two key dates from the Federal Reserve's response to the pandemic. For the FG events we follow Swanson (2020).

The event-study estimates in Table F.1 show that changes in policy uncertainty are a highly relevant second dimension of the Fed's recent unconventional policy announcements, including both QE and FG. The announcements of QE1 in late 2008 and early 2009 had substantial effects on asset prices, as has been extensively documented in the literature. The large declines in mps suggest that an important reason for these effects was that the expected path of the future policy rate was revised downward due to implicit and explicit signaling effects in these announcements (Bauer and Rudebusch, 2014). These announcements also lowered the uncertainty around the expected policy path very substantially, as $M P U$ fell by about 3-4 standard deviations, including the decline of about 13 bps on December 16, 2008, which is the second largest drop in our sample. Thus, signaling worked not only through first but also through second moments of the perceived distribution of future policy rates, which may help explain the very large effects on other asset prices. ${ }^{41}$ Another major FOMC policy action was the introduction of calendar-based FG on August 9, 2011, which caused a modest dovish policy surprise but a dramatic decline in policy uncertainty, indeed the largest decline in $M P U$ in our sample. Treasury yields plummeted, the stock market jumped, with a historically large decline in the VIX of 13 percentage/index points, and the dollar depreciated 1.5 percent against other major currencies. These large and significant asset price responses to the Fed's explicit FG language can be explained by the dramatic shift in the second moment of the perceived distribution of the future policy rate: The policy rate was already at the zero lower bound and thus changes in the second moment caused by the FOMC announcement became particularly important. Similarly, other FG announcements also generally reduced policy uncertainty and supported financial market conditions. On the flipside, the "taper tantrum" - the episode in mid-2013 of increased speculation about the timing of the end of QE, caused by public remarks of Chairman Bernanke about the tapering of asset purchasesincreased uncertainty and tightened financial conditions. Around the FOMC announcement and press conference on June 19, 2013 MPU increased, Treasury yields jumped and stock prices dropped. The SEP releases coinciding with the FOMC announcements in March and September 2015, discussed in more detail in Swanson (2020), featured dovish interest rate

\footnotetext{
${ }^{41} \mathrm{~A}$ caveat to this interpretation is that the decline in $M P U$ reflects not only changes in uncertainty about the fed funds rate but also about the future LIBOR-OIS spread, which undoubtedly played a role during this heightened financial stress episode.
} 
projections relative to market expectations, and lowered both the expected path as well as the uncertainty around this path. Long-term Treasury yields fell significantly in response, a final example of the impact of forward guidance on asset prices - this time in the form of the SEP dot plot - through changes in the second moments of the distribution of future policy rates.

Finally, the table also shows two dates from 2020. The March meeting where FOMC lowered the rate to zero and September meeting which gave specific guidance about staying at the zero lower bound. Both meetings lowered uncertainty and moved financial markets, with the March meeting having a susbstantially bigger effect. ${ }^{42}$

\section{G Signal extraction model}

Here we provide a simple signal extraction model for news about asset prices. The goal is to explain the importance of the level of uncertainty for the magnitude of the asset price response to monetary policy surprises - the interaction effects - that we documented in Section 4.

Consider that market's prior belief (before the FOMC announcement) about an asset's (unobservable) payoff $y$ given by

$$
y \sim N\left(\mu_{y}, \sigma_{y}^{2}\right)
$$

The FOMC meeting announcement is represented by a public signal $x$

$$
x=y+\eta, \quad \text { with } \eta \sim N\left(0, \sigma_{\eta}^{2}\right)
$$

After observing the public signal, the market's updated expectation about the payoff is

$$
E(y \mid x)=\frac{\sigma_{\eta}^{2}}{\sigma_{y}^{2}+\sigma_{\eta}^{2}} \mu_{y}+\frac{\sigma_{y}^{2}}{\sigma_{y}^{2}+\sigma_{\eta}^{2}} x
$$

The market's expectation is a weighted average of their prior information and the public signal with the weights depending on the informativeness of the two sources of information. The dependent variable in our regression analysis is the change in the asset price on FOMC announcement days. This is captured by the update in the expectation for the asset payoff after observing the public signal given by

$$
E(y \mid x)-E(y)=\frac{\sigma_{y}^{2}}{\sigma_{y}^{2}+\sigma_{\eta}^{2}}\left(x-\mu_{y}\right)
$$

where $x-\mu_{y}$ is surprise component of the public signal (i.e. monetary policy surprise). The regression with interaction coefficients measures how the response of asset prices to monetary policy surprise depends on the variance of the public signal (i.e. monetary policy uncertainty). Denoting $s_{x}=x-\mu_{y}$ and $s_{y}=E(y \mid x)-E(y)$, it is straightforward to show that this interaction

\footnotetext{
${ }^{42}$ The announcement in September 2020, with substantially revised forward guidance language as a result of the new policy framework, affected policy expectations and uncertainty at longer horizons, due to the nature of the guidance. As a result, our one-year uncertainty measure changed only little, and the two-year yield was unchanged. However, additional unreported results show a pronounced decline in longer-term expectations and uncertainty, as measured by Eurodollar futures rates and option-based uncertainty.
} 
coefficient is negative.

$$
\frac{\partial^{2} s_{y}}{\partial s_{x} \partial \sigma_{\eta}^{2}}=\frac{-\sigma_{y}^{2}}{\left(\sigma_{y}^{2}+\sigma_{\eta}^{2}\right)^{2}}<0
$$

In other words, asset prices respond less to the information in the monetary policy surprise when the monetary policy uncertainty is high.

It is helpful to compare our findings and explanation to recent work by Benamar et al. (2020), which documents that asset prices respond more strongly to macroeconomic news when uncertainty is high. While this results would seem to stand in contrast with our findings, it is based on a fundamentally different uncertainty measure, related to investors' information demand and their private signals, rather than the variance of a public signal. In fact, the theoretical framework in Benamar et al. (2020) is consistent with the implication that asset prices respond more strongly to news when the public signal is more informative. This implication is the one we focus on. 
Table D.3: The response of uncertainty to news releases

\begin{tabular}{lccc}
\hline & Dummy & Surprise & Abs. surprise \\
\hline FOMC & -0.018 & 0.012 & -0.009 \\
& {$[-8.77]$} & {$[5.00]$} & {$[-1.89]$} \\
Employment & -0.008 & 0.013 & 0.008 \\
CPI & {$[-3.97]$} & {$[3.46]$} & {$[1.21]$} \\
& -0.002 & 0.002 & 0.003 \\
PPI & {$[-1.25]$} & {$[1.16]$} & {$[1.30]$} \\
& -0.003 & 0.003 & 0.001 \\
Retail Sales & {$[-2.78]$} & {$[2.48]$} & {$[0.40]$} \\
& -0.001 & 0.002 & 0.001 \\
GDP & {$[-0.88]$} & {$[1.91]$} & {$[0.98]$} \\
& 0.001 & -0.001 & 0.006 \\
ISM & {$[0.39]$} & {$[-0.41]$} & {$[1.48]$} \\
& 0.006 & 0.003 & 0.001 \\
Constant & {$[3.76]$} & {$[2.10]$} & {$[0.36]$} \\
& 0.001 & 0.001 & 0.001 \\
Obs & {$[2.71]$} & {$[2.76]$} & {$[2.73]$} \\
$R^{2}$ & 5541 & 5541 & 5541 \\
\hline
\end{tabular}

Regression of change in $S R U$ on news release days. The first column reports results for a regression with dummy indicators for each news release. For the second column, we add the surprise components of the news release as regressors, and report the coefficients on the surprise component (the coefficients on the dummies are omitted). For "FOMC" the surprise is the first principal component of changes in futures rates, as explained in Section 3. For the macro releases, the surprise is the standardized difference between the released number and the consensus forecast from Action Economics/Money Market Services. For the employment report, we use non-farm payrolls, for CPI and PPI we use headline inflation, retail sales are the total sales including automobiles, "GDP" is the advance GDP release, and "ISM" is the Institute for Supply Management manufacturing survey. The third column reports results for a regression which uses absolute values of surprises instead of the actual surprises. The sample period is January 1994 to December 2017, excluding the period from July 2007 to June 2009 covering the Global Financial Crisis, with 5541 daily observations. In brackets are $t$-statistics calculated using White heteroskedasticity-robust standard errors. 
Table D.4: Summary statistics for days with speeches by FOMC members

\begin{tabular}{lcccc}
\hline & All speeches & Greenspan & Bernanke & Yellen \\
\hline Observations & 2137 & 120 & 156 & 60 \\
Mean & 0.00 & -0.00 & 0.00 & -0.00 \\
t-stat (mean) & 0.71 & -1.58 & 0.63 & -1.22 \\
Standard deviation & 0.02 & 0.02 & 0.03 & 0.01 \\
Cumulative change & 0.74 & -0.29 & 0.24 & -0.13 \\
\hline
\end{tabular}

Summary statistics for the change in short-rate uncertainty $(S R U)$ on Fed speech days. The first column considers a speech given by any member of the FOMC. The last three columns focus on the speech days of the previous three Fed chairs. The sample period is from January 1994 to December 2017.

Table D.5: Changes in uncertainty after FOMC meetings

\begin{tabular}{lcccccc}
\hline & ED1 & ED2 & ED3 & ED4 & ED5 & ED6 \\
\hline Constant & -0.30 & -0.33 & -0.35 & -0.38 & -0.34 & -0.36 \\
& {$[-6.09]$} & {$[-6.88]$} & {$[-6.66]$} & {$[-6.56]$} & {$[-5.71]$} & {$[-5.43]$} \\
FOMC & -1.58 & -1.46 & -1.54 & -1.47 & -1.42 & -1.08 \\
& {$[-9.45]$} & {$[-9.62]$} & {$[-8.58]$} & {$[-7.81]$} & {$[-7.24]$} & {$[-5.40]$} \\
W1 & 0.03 & 0.18 & 0.22 & 0.26 & 0.21 & 0.22 \\
& {$[0.43]$} & {$[2.62]$} & {$[2.88]$} & {$[3.12]$} & {$[2.49]$} & {$[2.33]$} \\
W2 & 0.07 & 0.18 & 0.23 & 0.29 & 0.29 & 0.32 \\
& {$[0.99]$} & {$[2.43]$} & {$[2.83]$} & {$[3.38]$} & {$[3.29]$} & {$[3.37]$} \\
W3 & -0.12 & -0.04 & -0.03 & 0.02 & -0.06 & 0.06 \\
& {$[-1.70]$} & {$[-0.56]$} & {$[-0.33]$} & {$[0.21]$} & {$[-0.63]$} & {$[0.60]$} \\
W4 & -0.11 & 0.02 & 0.04 & 0.03 & 0.05 & 0.09 \\
& {$[-1.61]$} & {$[0.26]$} & {$[0.52]$} & {$[0.40]$} & {$[0.64]$} & {$[0.98]$} \\
W5 & -0.08 & 0.01 & 0.03 & 0.08 & 0.10 & 0.14 \\
& {$[-1.11]$} & {$[0.15]$} & {$[0.38]$} & {$[0.99]$} & {$[1.13]$} & {$[1.51]$} \\
\hline$R^{2}$ & 0.041 & 0.028 & 0.026 & 0.023 & 0.020 & 0.013 \\
Observations & 4872 & 6178 & 6180 & 6180 & 6180 & 5364 \\
\hline
\end{tabular}

Regressions of changes in uncertainty $\left(\Delta S R U_{t, T}\right)$ from fixed-expiration Eurodollar contracts, multiplied by 100, on dummy variables for days with FOMC announcements (FOMC), with an FOMC meeting 1-5 trading days ago (W1), 6-10 days ago (W2), etc. t-statistics in squared brackets are calculated using White heteroskedasticity-robust standard errors. Sample period: January 1994 and September 2020, excluding the period from July 2007 to June 2009 covering the Global Financial Crisis (some observations are missing for contracts ED1, ED2 and ED6 due to option data availability). 
Table E.1: Hanson and Stein (2015) regressions for Treasury forward rates

\begin{tabular}{|c|c|c|c|c|c|c|c|c|}
\hline \multirow[b]{3}{*}{$M P S$} & \multicolumn{4}{|c|}{ Nominal } & \multicolumn{4}{|c|}{ Real } \\
\hline & \multicolumn{2}{|c|}{5 year } & \multicolumn{2}{|c|}{10 year } & \multicolumn{2}{|c|}{5 year } & \multicolumn{2}{|c|}{10 year } \\
\hline & $\begin{array}{c}1.03 \\
{[11.80]}\end{array}$ & $\begin{array}{c}1.52 \\
{[5.08]}\end{array}$ & $\begin{array}{c}0.57 \\
{[7.74]}\end{array}$ & $\begin{array}{c}0.45 \\
{[1.90]}\end{array}$ & $\begin{array}{c}1.05 \\
{[5.82]}\end{array}$ & $\begin{array}{c}2.58 \\
{[5.36]}\end{array}$ & $\begin{array}{c}0.41 \\
{[2.34]}\end{array}$ & $\begin{array}{c}0.36 \\
{[0.60]}\end{array}$ \\
\hline$M P U$ & & $\begin{array}{c}0.87 \\
{[3.41]}\end{array}$ & & $\begin{array}{c}0.51 \\
{[1.96]}\end{array}$ & & $\begin{array}{c}1.06 \\
{[4.14]}\end{array}$ & & $\begin{array}{c}0.50 \\
{[1.66]}\end{array}$ \\
\hline$M P S \times S R U_{-1}$ & & $\begin{array}{l}-0.68 \\
{[-2.26]}\end{array}$ & & $\begin{array}{c}0.01 \\
{[0.02]}\end{array}$ & & $\begin{array}{l}-2.03 \\
{[-2.95]}\end{array}$ & & $\begin{array}{l}-0.07 \\
-0.11\end{array}$ \\
\hline$R^{2}$ & 0.43 & 0.50 & 0.17 & 0.19 & 0.30 & 0.44 & 0.08 & 0.10 \\
\hline
\end{tabular}

Event study regressions for forward rates on FOMC announcement days, using the variable definitions of Hanson and Stein (2015). Regressions of two-day changes in Treasury forward rates on (i) the monetary policy surprise MPS (measured as the two-day change in the two-year Treasury yield), (ii) the two-day change in monetary policy uncertainty $(M P U)$, and (iii) $M P U$ interacted with the level of short-rate uncertainty on the day before the FOMC meeting $\left(S R U_{-1}\right)$. In the second specification we also include $S R U_{-1}$ but don't report its coefficient to economize on space (as for all estimated constants). In brackets are $t$-statistics based on White heteroscedasticity-robust standard errors. The sample for nominal forwards contains 197 scheduled FOMC announcements from February 1994 to September 2020 while the sample for the real forwards contains 157 observations from February 1999 to September 2020, Both exclude the period from July 2007 to June 2009 containing the Global Financial Crisis.

Table E.2: Response of asset prices to uncertainty, controlling for target and path factor

\begin{tabular}{lccccc}
\hline & 5 year yield & 10 year yield & Stock & VIX & Dollar \\
\hline Target Factor & -0.17 & -0.22 & -7.64 & 13.35 & 1.54 \\
& {$[-0.82]$} & {$[-0.83]$} & {$[-1.19]$} & {$[1.31]$} & {$[0.31]$} \\
Path Factor & 1.37 & 0.82 & -10.62 & 15.85 & 13.29 \\
& {$[9.24]$} & {$[4.60]$} & {$[-2.82]$} & {$[2.66]$} & {$[6.42]$} \\
$M P U$ & 0.59 & 0.69 & -11.06 & 27.57 & 5.52 \\
& {$[3.20]$} & {$[3.00]$} & {$[-2.15]$} & {$[1.99]$} & {$[3.90]$} \\
Target x $S R U_{-1}$ & 0.14 & 0.15 & 5.71 & -11.07 & -1.46 \\
& {$[0.97]$} & {$[0.69]$} & {$[1.21]$} & {$[-1.51]$} & {$[-0.40]$} \\
Path x $S R U_{-1}$ & -0.60 & -0.32 & 8.46 & -15.50 & -10.12 \\
& {$[-4.57]$} & {$[-1.81]$} & {$[2.42]$} & {$[-2.46]$} & {$[-5.94]$} \\
$R^{2}$ & 0.67 & 0.44 & 0.13 & 0.21 & 0.34 \\
\hline
\end{tabular}

Regressions of daily changes in various asset prices on the target and path factor from Gürkaynak et al. (2005a), the change in uncertainty $(M P U)$, and the target and path factors interacted with the ex-ante level (measured on day before announcement) of uncertainty $\left(S R U_{-1}\right)$ on scheduled FOMC announcement days. We also include $S R U_{-1}$ but don't report its coefficient to economize on space (as for all estimated constants). In brackets are $t$-statistics based on White heteroscedasticity-robust standard errors. The sample contains 197 scheduled FOMC announcements from January 1994 to September 2020, excluding the period from July 2007 to June 2009 covering the Global Financial Crisis. The dollar index sample (176 announcements) ends in December 2017. 
Table E.3: Response of term premia to monetary policy uncertainty

\begin{tabular}{|c|c|c|c|c|c|c|c|c|}
\hline \multirow[b]{3}{*}{$M P S$} & \multicolumn{4}{|c|}{ ACM Term Premium } & \multicolumn{4}{|c|}{ KW Term Premium } \\
\hline & \multicolumn{2}{|c|}{5 year } & \multicolumn{2}{|c|}{10 year } & \multicolumn{2}{|c|}{5 year } & \multicolumn{2}{|c|}{10 year } \\
\hline & 0.07 & -0.01 & -0.03 & -0.1 & 0.20 & 0.14 & 0.21 & 0.14 \\
\hline & {$[1.97]$} & {$[-0.24]$} & {$[-0.49]$} & {$[-2.04]$} & [6.19] & {$[4.08]$} & 6.20 & {$[3.71]$} \\
\hline \multirow[t]{2}{*}{$M P U$} & & 0.43 & & 0.52 & & 0.27 & & 0.36 \\
\hline & & {$[2.68]$} & & {$[2.42]$} & & {$[2.55]$} & & {$[2.70]$} \\
\hline$R^{2}$ & 0.02 & 0.10 & 0.00 & 0.06 & 0.30 & 0.36 & 0.25 & 0.32 \\
\hline
\end{tabular}

Regressions of daily changes in term premia on 5 and 10 year Treasury yields (ACM from Adrian et al. (2013) and KW from Kim and Wright (2005)) on the monetary policy surprise MPS and the change in policy uncertainty $M P U$ on FOMC announcement days. Constants are included in the regressions but not reported here. In brackets are $t$-statistics based on White heteroscedasticity-robust standard errors. The sample contains 197 scheduled FOMC announcements from January 1994 to September 2020, excluding the period from July 2007 to June 2009 containing the Global Financial Crisis.

Table F.1: Event study of quantitative easing and forward guidance

\begin{tabular}{ccccccccc}
\hline Date & Event & MPU & MPS & 5y yld & 10y yld & S\&P 500 & VIX & Dollar \\
\hline $11 / 25 / 2008$ & QE1 & -0.10 & -0.16 & -0.22 & -0.21 & 0.65 & -3.80 & -0.67 \\
$12 / 16 / 2008$ & QE1/FG & -0.13 & -0.25 & -0.16 & -0.17 & 5.01 & -4.39 & -2.35 \\
$3 / 18 / 2009$ & QE1/FG & -0.08 & -0.19 & -0.47 & -0.52 & 2.06 & -0.74 & -2.82 \\
$11 / 3 / 2010$ & QE2 & -0.03 & 0.00 & -0.04 & 0.04 & 0.37 & -2.01 & -0.56 \\
$8 / 9 / 2011$ & FG & -0.14 & -0.03 & -0.19 & -0.21 & 4.63 & -12.94 & -1.54 \\
$9 / 21 / 2011$ & MEP & 0.00 & 0.05 & 0.02 & -0.08 & -2.98 & 4.46 & 1.64 \\
$1 / 25 / 2012$ & FG & -0.02 & 0.00 & -0.09 & -0.08 & 0.86 & -0.60 & -0.46 \\
$9 / 13 / 2012$ & QE3/FG & -0.02 & 0.01 & -0.04 & -0.03 & 1.62 & -1.75 & -0.54 \\
$12 / 12 / 2012$ & FG & 0.00 & 0.01 & 0.02 & 0.06 & 0.04 & 0.38 & -0.21 \\
$6 / 19 / 2013$ & Taper Tantrum & 0.01 & 0.04 & 0.17 & 0.14 & -1.39 & 0.03 & 0.93 \\
$12 / 17 / 2014$ & FG & -0.01 & 0.03 & 0.08 & 0.08 & 2.01 & -4.13 & 0.97 \\
$3 / 18 / 2015$ & FG & -0.04 & -0.06 & -0.15 & -0.12 & 1.21 & -1.69 & -1.90 \\
$9 / 17 / 2015$ & FG & -0.04 & -0.08 & -0.12 & -0.09 & -0.26 & -0.21 & -0.53 \\
$3 / 15 / 2020$ & FG & -0.03 & -0.05 & -0.21 & -0.23 & -12.77 & 24.86 & -0.24 \\
$9 / 16 / 2020$ & FG & -0.01 & 0.02 & 0.01 & 0.01 & -0.46 & 0.45 & \\
\hline Std. dev. (full sample) & 0.03 & 0.08 & 0.08 & 0.08 & 1.67 & 2.63 & 0.60 \\
\hline
\end{tabular}

Changes in asset prices on selected days with major FOMC announcements about unconventional monetary policy, including the three large-scale asset purchase programs, or quantitative easing (QE), the maturity extension program (MEP), and forward guidance (FG). $M P U$ are daily changes in monetary policy uncertainty, $M P S$ is the monetary policy surprise based on changes in Eurodollar futures rates. 